\title{
The tropical Pacific cold tongue mode and its associated main ocean dynamical process in CMIP5 models
}

\author{
Yang Li ${ }^{1}$, QuanLiang Chen ${ }^{1}{ }^{*}$, JianPing Li ${ }^{2}$, WenJun Zhang ${ }^{3}$, MinHong Song ${ }^{1}$, Wei Hua ${ }^{1}$, HongKe Cai ${ }^{1}$, and XiaoFei Wu' \\ ${ }^{1}$ College of Atmospheric Science, Plateau Atmosphere and Environment Key Laboratory of Sichuan Province, Chengdu University of Information Technology, \\ Chengdu 610225, China; \\ ${ }^{2}$ Key Laboratory of Physical Oceanography-Institute for Advanced Ocean Studies, Ocean University of China and Qingdao National Laboratory for Marine \\ Science and Technology, Qingdao 266100, China; \\ ${ }^{3}$ Collaborative Innovation Center on Forecast and Evaluation of Meteorological Disasters, Key Laboratory of Meteorological Disaster of Ministry of Education, \\ Nanjing University of Information Science and Technology, Nanjing 210044, China
}

\begin{abstract}
The cold tongue mode (CTM), which represents the out-of-phase relationship in sea surface temperature anomaly (SSTA) variability between the Pacific cold tongue region and elsewhere in the tropical Pacific, shows a long-term cooling trend in the eastern equatorial Pacific. In this study, we investigate how well the CTM is reproduced in historical simulations generated by the 20 models considered in Phase 5 of the Coupled Model Intercomparison Project (CMIP5). Qualitatively, all 20 models roughly capture the cooling SSTA associated with the CTM. However, a quantitative assessment (i.e., Taylor diagrams and the ratio of the trend between the simulations and observations) shows that only five of these 20 models (i.e., CESM1-CAM5, CMCC-CM, FGOALS-g2, IPSL-CM5B-LR, and NorESM1-M) can reproduce with useful accuracy the spatial pattern and long-term trend of the CTM. We find that these five models generally simulate the main ocean dynamical process associated with the CTM. That is, these models adequately capture the long-term cooling trend in the vertical advection of the anomalous temperature by the mean upwelling. We conclude that the performance of these CMIP5 models, with respect to simulations of the long-term cooling trend associated with the vertical advection, and the related long-term decreasing trend of the vertical gradient of the oceanic temperature anomaly, can play an important role in successful reproduction of the CTM.
\end{abstract}

Keywords: tropical Pacific; La Niña-like; cold tongue mode; ocean dynamical process; CMIP5

Citation: Li, Y., Chen, Q. L., Li, J. P., Zhang, W. J., Song, M. H., Hua, W., Cai, H. K., and Wu, X. F. (2019). The tropical Pacific cold tongue mode and its associated main ocean dynamical process in CMIP5 models. Earth Planet. Phys., 3(5), 400-413. http://doi.org/10.26464/epp2019041

\section{Introduction}

In recent years, El Niño-Southern Oscillation (ENSO) diversity, representing differences in the sea surface temperature anomalies (SSTA) of ENSO events, has been a topic of great interest (e.g., Karnauskas, 2013; Ren HL and Jin FF, 2013; Ren HL et al., 2013, 2016a; Zhang WJ et al., 2013, 2014; Zheng F et al., 2014, 2016; Capotondi et al., 2015; Zheng F and Yu JY, 2017). Many studies have pointed out that the tropical Pacific background state makes an important contribution to ENSO diversity under global warming (Ashok et al., 2007; Yeh et al., 2009; Collins et al., 2010; Duan WS et al., 2014; Li Y et al., 2017; Lemmon and Karnauskas, 2018). Numerous studies have reported that the tropical Pacific background state is similar to a La Niña-like pattern (i.e., greater warming in the west than the east) and that it plays an important role in ENSO diversity (Duan WS et al., 2014; Li Y et al., 2017; Jiang N and Zhu CW, 2018; Lemmon and Karnauskas, 2018).

Correspondence to: Q. L. Chen, chenql@cuit.edu.cn

Received 03 MAY 2019; Accepted 09 JUL 2019.

Accepted article online 26 JUL 2019.

(C) 2019 by Earth and Planetary Physics.
Although there is disagreement about the relationship between the long-term trend of tropical Pacific and global warming (Collins et al., 2010), the La Niña-like pattern has been confirmed by many observations. For example, Li Y et al. (2017) reported that the subsurface temperature of the eastern equatorial Pacific is cooler than that of the western equatorial Pacific; Karnauskas et al. (2009) and Coats and Karnauskas (2017) pointed out that many datasets indicate a strengthening of the equatorial Pacific zonal SST gradient. Meanwhile, the equatorial undercurrent and subtropical cells associated with the La Niña-like pattern have been demonstrated to be accelerating (Drenkard and Karnauskas, 2014; Yang CX et al., 2014; Coats and Karnauskas, 2018). Some atmospheric evidence also supports the La Niña-like pattern, such as the strengthening of Walker circulation and trades (L'Heureux et al., 2013; Li Y et al., 2019). These results indicate that the La Niña-like condition plays a dominant role in the tropical Pacific under global warming (Cane et al., 1997).

Many studies have demonstrated that the second EOF mode of the tropical Pacific can present a La Niña-like pattern under global warming (Zhang WJ et al., 2010; Li JP et al., 2013; Duan WS et al., 2014; Li Y et al., 2015, 2017, 2019; Lemmon and Karnauskas, 2019). 
As shown in Figure 1, the second EOF mode represents an out-ofphase relationship in SSTA variability between the Pacific cold tongue region and the rest of the tropical Pacific. Its spatial pattern is consistent with the La Niña-like pattern (Fig. 5 in Solomon and Newman, 2012), and its normalized principal components
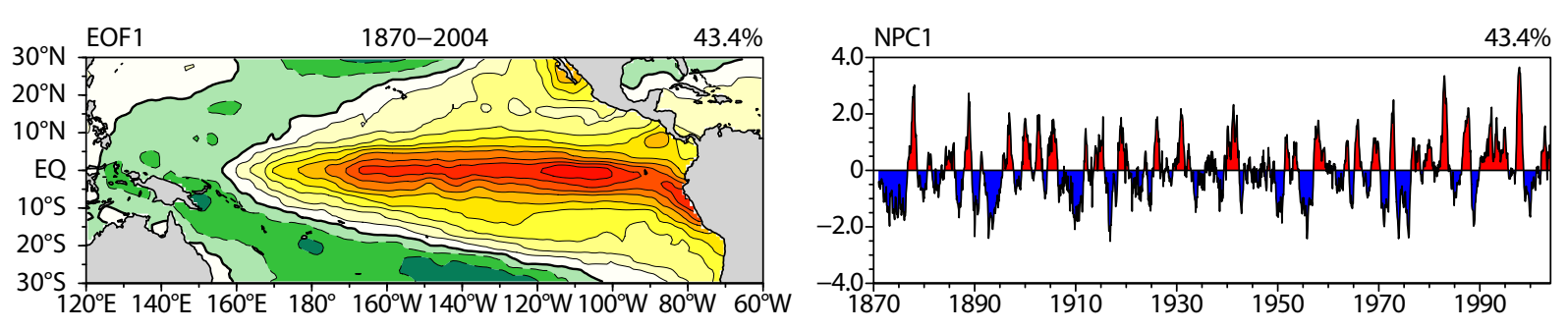

(NPC2) show a strong long-term trend. This means that there is a cooling cold tongue region under global warming. In addition, it can be seen from Figure 1 that ENSO is identified by the first EOF mode, with strong interannual variability (Deser et al., 2009; Compo and Sardeshmukh, 2010; Zhang WJ et al., 2010).

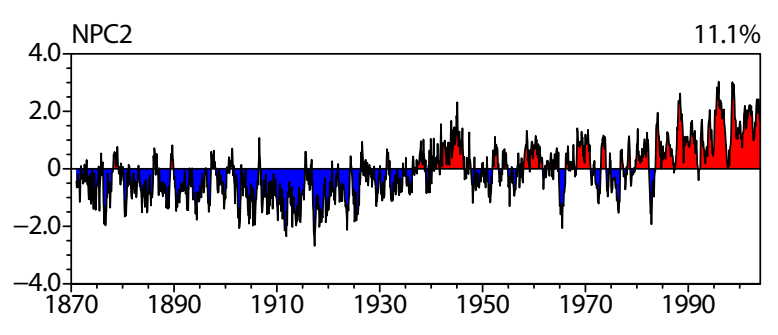

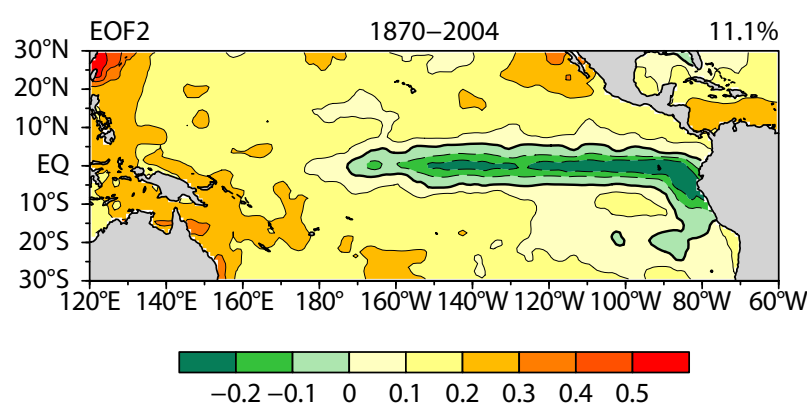

Figure 1. The spatial patterns and corresponding normalized PCs of the first two leading EOF modes of the tropical Pacific SSTA $\left({ }^{\circ} \mathrm{C}\right)$ for the HadISST1 dataset.

Following previous studies (Zhang WJ et al., 2010; Li JP et al., 2013; Li $Y$ et al., 2015, 2017, 2019; Jiang $N$ and Zhu CW, 2018), the second EOF mode is referred to as the cold tongue mode (CTM). $\mathrm{Li}$ $Y$ et al. (2015) emphasized that "the long-term trend of the CTM is dominated by the vertical advection of the anomalous temperature by the mean upwelling $\left(-\bar{w} \partial T^{\prime} / \partial z\right)^{\prime \prime}$. Although net heat flux and other ocean dynamical processes also contribute to the CTM, the effect of the $-\bar{w} \partial T^{\prime} / \partial z$ term is the main ocean dynamical process in the CTM.

It is noted that the CTM has been identified not only in observations, but also in climate models. Zhang WJ et al. (2010) pointed out that the CTM is accurately simulated in the 20th century run of some Phase 3 models in the Coupled Model Intercomparison Project (CMIP3). The current Phase 5 CMIP (CMIP5) models have higher spatial resolution relative to those in CMIP3 (Taylor et al., 2012). In addition, the CMIP5 models have improved the simulation of climate variability; some are able to capture important climate phenomena in the Pacific, for example ENSO (Kim and Yu JY, 2012; Kug et al., 2012; Zhang WJ and Jin FF, 2012; Bellenger et al., 2014; Ren HL et al., 2016b; Lin RP et al., 2018), Pacific Decadal Oscillation (PDO) (Newman et al., 2016), and the La Niña-like pattern (Funk and Hoell, 2015). However, no research has been devoted to investigating the CTM in the CMIP5 simulations. Consequently, in this study we aim to address two main issues: How well do the CMIP5 models reproduce the CTM pattern and its long-term trend? If some models reproduce the CTM well, how well do these models reproduce the main ocean dynamical process associated with the CTM?
The remainder of this paper is organized as follow. Section 2 introduces the data and methods used in this study. An analysis of the performance of the models in reproducing the historical CTM is presented in Section 3. The performance of the models in reproducing the main ocean dynamical process associated with the CTM is discussed in Section 4. Finally, discussion and conclusions are presented in Section 5.

\section{Data and Methods}

\subsection{Data}

We used monthly SST from UK Met Office's Hadley Centre Sea Ice and SST version 1 (HadISST1) dataset (Rayner et al., 2003). We analyzed simulations from the 20 models that participated in CMIP5. The model output and information, including their developing centers and horizontal resolutions, are listed in Table 1. To evaluate the performance of the models in reproducing the CTM, we used monthly output over the period 1870-2004 from historical simulations ( $\mathrm{r} 1 \mathrm{i} 1 \mathrm{p} 1$ ), which were forced by observed atmospheric composition changes from natural and anthropogenic sources (Taylor et al., 2012). As the ocean component of most models used a tripolar global grid, the modeled outputs of ocean variables (SST, ocean subsurface temperature, and upwelling) were interpolated onto a common rectangular grid of $1.0^{\circ} \times 1.0^{\circ}$ prior to further calculations. Note that the mean seasonal cycle of all datasets from 1961 to 1990 was removed and that our results are not sensitive to the choices of mean seasonal cycle. 
Table 1. Basic details of the CMIP5 models used in this study

\begin{tabular}{|c|c|c|c|}
\hline \multirow[t]{2}{*}{ Name } & \multirow[t]{2}{*}{ Model center/Country } & \multicolumn{2}{|c|}{$\begin{array}{c}\text { Resolution } \\
\text { (Latitude }\left({ }^{\circ}\right) \times \text { Longitude }\left({ }^{\circ}\right) \text { ) }\end{array}$} \\
\hline & & Atmosphere & Ocean \\
\hline ACCESS1-3 & $\begin{array}{l}\text { Commonwealth Scientific and Industrial Research Organization (CSIRO) and } \\
\text { Bureau of Meteorology (BOM)/Australia }\end{array}$ & $145 \times 192$ & $300 \times 360$ \\
\hline BCC-CSM1-1-M & Beijing Climate Center (BCC), China Meteorological Administration (CMA)/China & $160 \times 320$ & $232 \times 360$ \\
\hline BNU-ESM & $\begin{array}{l}\text { College of Global Change and Earth System Science (GCESS), Beijing Normal } \\
\text { University (BNU)/China }\end{array}$ & $64 \times 128$ & $200 \times 360$ \\
\hline CanESM2 & Canadian Centre for Climate Modeling and Analysis (CCCMA)/Canada & $64 \times 128$ & $192 \times 256$ \\
\hline CCSM4 & National Center for Atmospheric Research (NCAR)/United States & $192 \times 288$ & $384 \times 320$ \\
\hline CESM1-BGC CESM1-CAM5 & $\begin{array}{l}\text { National Science Foundation (NSF), Department of Energy (DOE), NCAR/United } \\
\text { States }\end{array}$ & $192 \times 288$ & $384 \times 320$ \\
\hline CMCC-CM & Centro Euro-Mediterraneo per 1 Cambiamenti Climatici (CMCC)/Italy & $240 \times 480$ & $149 \times 182$ \\
\hline FGOALS-g2 & $\begin{array}{l}\text { State Key Laboratory of Numerical Modeling for Atmospheric Sciences and } \\
\text { Geophysical Fluid Dynamics (LASG), Institute of Atmospheric Physics (IAP), } \\
\text { Chinese Academy of Sciences (CAS)/China }\end{array}$ & $60 \times 128$ & $196 \times 360$ \\
\hline GFDL-ESM2G & $\begin{array}{l}\text { National Oceanic and Atmospheric Administration (NOAA) Geophysical Fluid } \\
\text { Dynamics Laboratory (GFDL)/United States }\end{array}$ & $90 \times 144$ & $210 \times 360$ \\
\hline GISS-E2-H GISS-E2-H-CC & $\begin{array}{l}\text { National Aeronautics and Space Administration (NASA) Goddard Institute for } \\
\text { Space Studies (GISS)/United States }\end{array}$ & $90 \times 144$ & $90 \times 144$ \\
\hline HadGEM2-CC HadGEM2-ES & $\begin{array}{l}\text { Met Office Hadley Centre (MOHC; additional HadGEM2-ES realizations } \\
\text { contributed by Instituto Nacional de Pesquisas Espaciais)/United Kingdom }\end{array}$ & $145 \times 192$ & $216 \times 360$ \\
\hline INM-CM4 & Institute for Numerical Mathematics (INM)/Russia & $120 \times 180$ & $340 \times 360$ \\
\hline IPSL-CM5A-LR IPSL-CM5B-LR & Institut Pierre-Simon Laplace (IPSL)/France & $96 \times 96$ & $149 \times 182$ \\
\hline MPI-ESM-P & Max Planck Institute for Meteorology (MPI-M)/Germany & $96 \times 192$ & $220 \times 256$ \\
\hline NorESM1-M NorESM1-ME & Norwegian Climate Centre (NCC)/Norway & $96 \times 144$ & $384 \times 320$ \\
\hline
\end{tabular}

\subsection{Methods}

To avoid the impact of outliers on trend estimation, trends were calculated as the Theil-Sen median slope (Sen, 1968; Theil, 1992) and tested for statistical significance using the Mann-Kendall test. Note that the Theil-Sen trend estimation method is measured by the median of slopes between all pairs and that it was determined using the following equation:

$$
\begin{aligned}
& \text { trend }=\operatorname{Median}\left(\frac{x_{i}-x_{j}}{i-j}\right), \\
& \forall j<i, 1 \leqslant j<i \leqslant N
\end{aligned}
$$

where trend is the Theil-Sen trend, $x_{i}$ and $x_{j}$ are one data pair, and $N$ is the sample size.

In addition, we used the partial correlation coefficient (PR) to detect the relationship between each pair of variables after excluding the effect of the third variable. Moreover, linear regression was used to remove the specific signal. Note that the PR and removal related to linear regression can exclude only linear components but not nonlinear interactions (Zheng F et al., 2015).

\section{Performance of CMIP5 Models in Reproducing the CTM}

\subsection{ENSO Mode Simulated by CMIP5 Models}

As mentioned above, the first EOF mode over the tropical Pacific represents the ENSO mode (Deser et al., 2009; Compo and Sardeshmukh, 2010; Zhang WJ et al., 2010), and the second EOF mode depicts the CTM (Zhang WJ et al., 2010; Li JP et al., 2013; Duan WS et al., 2014; Li Y et al., 2015, 2017). ENSO represents the interannual variability of ocean dynamical processes (Collins et al., 2010), while the CTM is dominated by the long-term change of ocean dynamical processes (Zhang WJ et al., 2010; Li JP et al., 2013; Li Y et al., 2015, 2017). It is suggested that the simulation of ENSO may play an important role in reproducing the CTM (Zhang et al., 2010). Therefore, we first assess the ENSO mode before examining the performance of CMIP5 models in reproducing the CTM. This approach is similar to that of Zhang WJ et al. (2010).

Figure 2 shows the first EOF modes of SSTA over the tropical Pacific and their corresponding NPC1 time series that are simulated by each of the 20 CMIP5 models. Qualitatively, it can be seen from Figure 2 that the spatial pattern of the ENSO mode is not captured by six of the models (i.e., BCC-CSM1-1-M, CanESM2, CCSM4, GISS-E2-H, IPSL-CM5A-LR, and MPI-ESM-P). This is because these six models show a warming SSTA across almost the whole tropical Pacific, and their time series exhibit no significant interannual variability and are dominated by a rising trend in SSTA (Figure 2). In particular, for four of the models (i.e., CanESM2, GISS-E2-H, IPSLCM5A-LR, and MPI-ESM-P), their time series almost correspond to a strong warming trend (Figure 2). According to previous research (Zhang WJ et al., 2010), the most plausible cause of this res- 

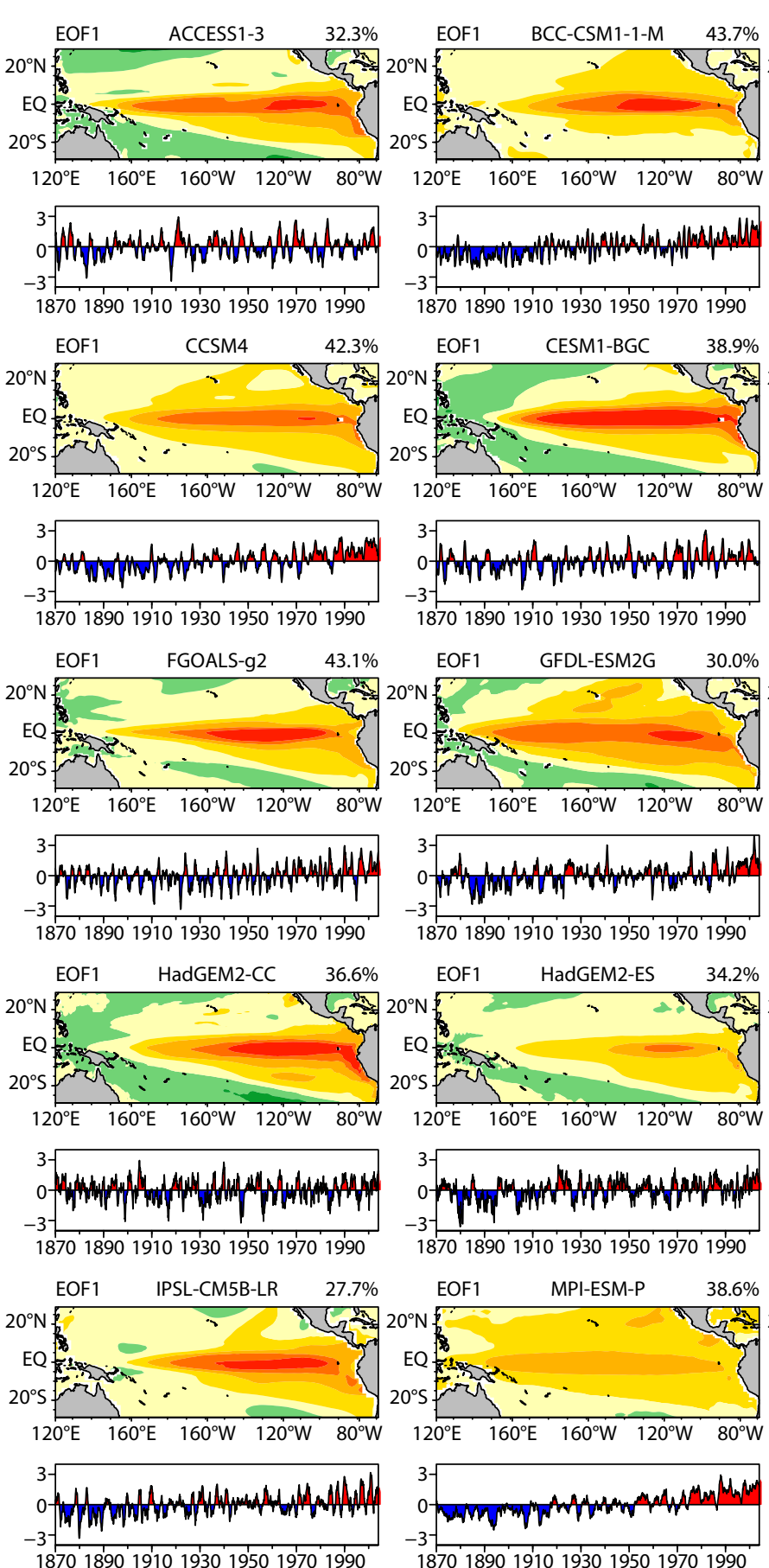

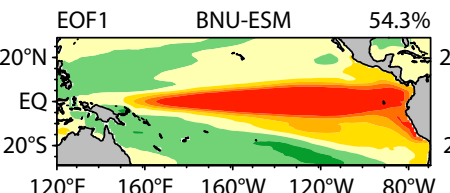

$120^{\circ} \mathrm{E} \quad 160^{\circ} \mathrm{E} \quad 160^{\circ} \mathrm{W} \quad 120^{\circ} \mathrm{W} \quad 80^{\circ} \mathrm{W}$

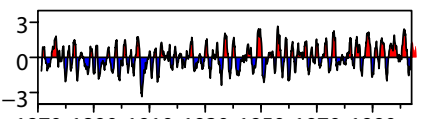

1870189019101930195019701990

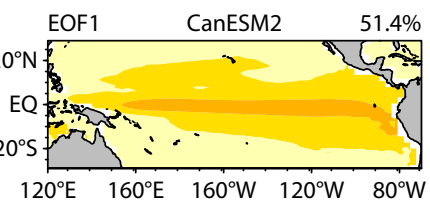

$120^{\circ} \mathrm{E} \quad 160^{\circ} \mathrm{E} \quad 160^{\circ} \mathrm{W} \quad 120^{\circ} \mathrm{W} \quad 80^{\circ} \mathrm{W}$

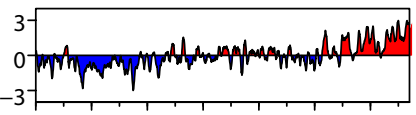

1870189019101930195019701990
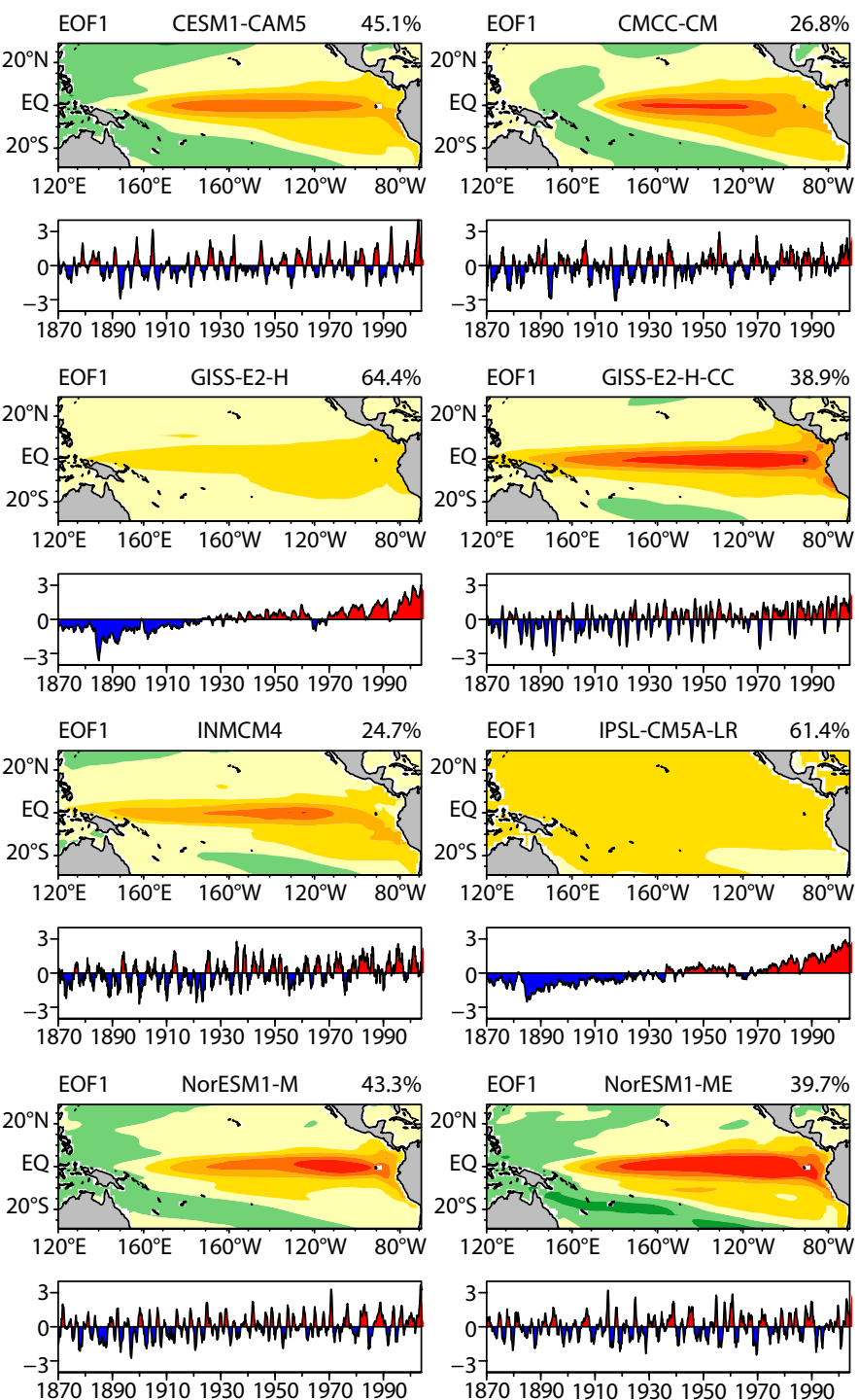

0.2

0.4

0.6

0.8

Figure 2. The first EOF modes in SSTA $\left({ }^{\circ} \mathrm{C}\right)$ over the tropical Pacific and their corresponding NPC1 time series for the historical simulations. The model names and variances are shown above each EOF mode.

ult is that the interannual signal of the ENSO mode is hidden by global warming.

To quantitatively examine the accordance between the CMIP5 models and the observations, a pair of Taylor diagrams (Taylor, 2001) is used to compare the performance of the models based on the spatial pattern of the ENSO mode. For the six models named above, the corresponding ratios of the standard deviation of the modeled and observed ENSO patterns are less than 0.75
(Figure 3a). Using root-mean-square (RMS) differences between the simulations and the observations, shown as the distance between the model point and the "REF" point in the Taylor diagram, the distances obtained for these six models are approximately greater than 0.5 (Figure $3 a$ ). This supports the conclusion that these six models perform less well in reproducing the observed ENSO pattern.

Aside from the above six models, three models (i.e., BNU-ESM, GF- 

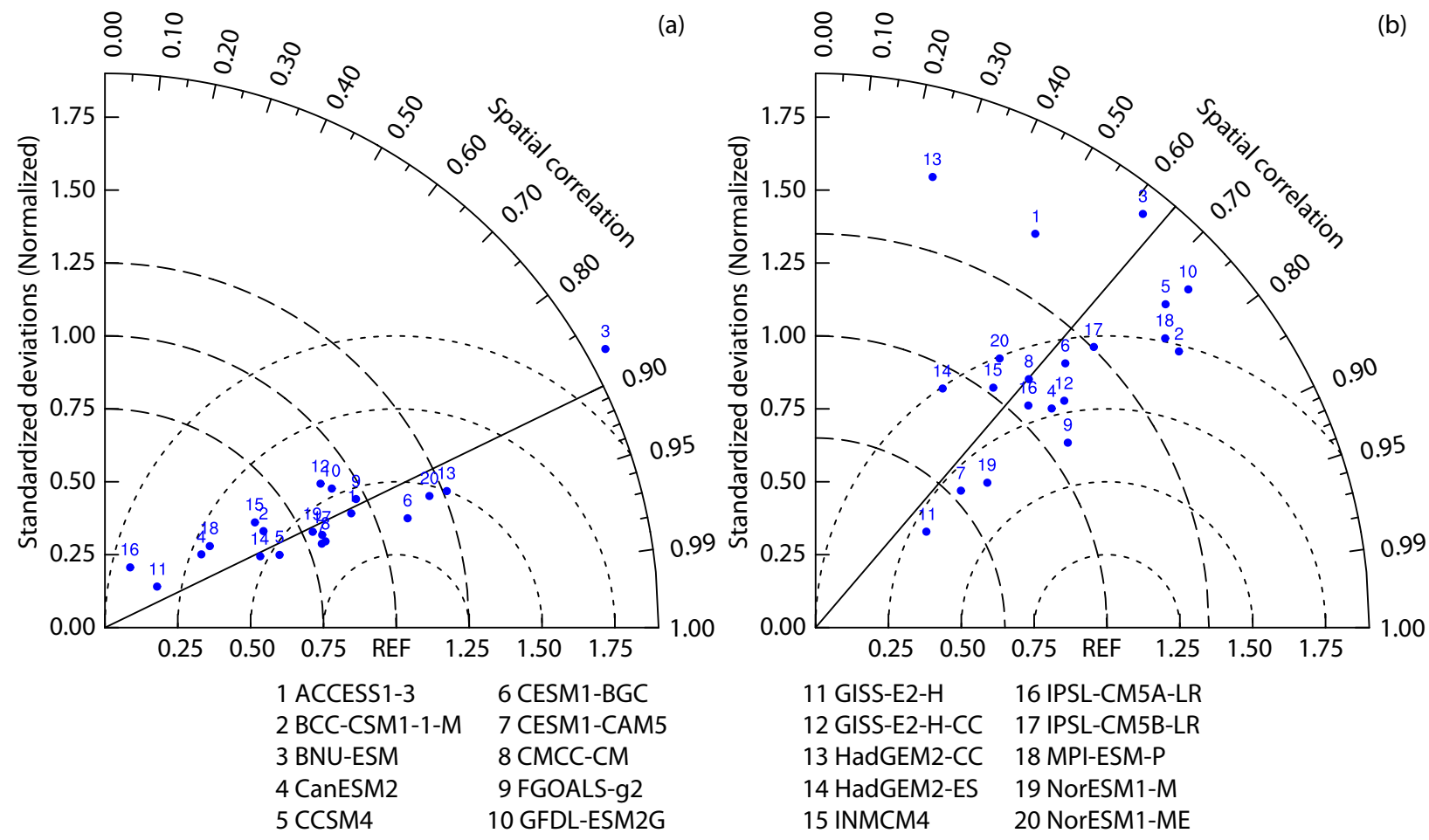

Figure 3. Taylor diagram of the (a) ENSO pattern and (b) CTM pattern. Each numbered dot represents a single model. The term "REF" on the horizontal axis indicates the reference point. Black solid lines and dashed arcs indicate the correlation coefficient and ratio of standard deviations, respectively, between modeled and observed (HadISST1) ENSO/CTM pattern. Black dotted arcs show the centered root mean square difference that is equal to the radial distance from the reference point.

DL-ESM2G, and GISS-E2-H-CC) tend towards strong interannual variability in the western equatorial Pacific (Figure 2). Correspondingly, the RMS differences of these six models are approximately larger than 0.5 (Figure 3a). In particular, BNU-ESM generates an RMS difference of more than 1.0 (Figure 3a). Meanwhile, another two models (i.e., HadGEM2-ES and INMCM4) underestimate the amplitude of the ENSO mode (Figure 2). This can be seen from the ratios of the standard deviation of the modeled and observed ENSO patterns, whose values are just about 0.5 (Figure $3 a$ ).

Another important aspect of the behavior of ENSO is its spectral characteristics; i.e., ENSO shows an interannual variability. Here, we use the continuous power spectrum to examine periodicity of ENSO mode in the observation and performance of the CMIP5 models in reproducing the spectral structure of the ENSO mode. The NPC1 of ENSO mode in the observation shows a significant periodicity of 2-4 years. In summary, most of the models capture the observed spectral peak at 2-4 years (Figure 4), except for the six models mentioned above (i.e., BCC-CSM1-1-M, CanESM2, CCSM4, GISS-E2-H, IPSL-CM5A-LR, and MPI-ESM-P), which all have spectral peaks at very low frequency. This corresponds to the strong long-term trend of the time series in these six models. It further suggests that the interannual signal of these six models is masked by global warming.

Overall, 11 models (i.e., BCC-CSM1-1-M, BNU-ESM, CanESM2, CCSM4, GFDL-ESM2G, GISS-E2-H, GISS-E2-H-CC, HadGEM2-ES, INMCM4, IPSL-CM5A-LR, and MPI-ESM-P) are not able accurately to capture the spatial or temporal characteristic of the ENSO mode (Figures $3 \mathrm{a}$ and 4). The remaining nine models (i.e., ACCESS1-3,
CESM1-BGC, CESM1-CAM5, CMCC-CM, FGOALS-g2, HadGEM2-CC, IPSL-CM5B-LR, NorESM1-M, and NorESM1-ME) perform well in reproducing both the observed spatial pattern and the interannual variations of the ENSO mode. It can be seen from Figure 3a that the distances between the points associated with these nine models and the "REF" point are generally smaller than those of the other 11 models. Also, these nine models exhibit peaks over interannual scales of about 2-4 years.

\subsection{CTM Simulated by CMIP5 Models}

As discussed above, we first analyze the performance of the CMIP5 models in reproducing the ENSO mode. Next, we consider how well the CMIP5 models reproduce the spatial and temporal characteristics of the CTM. We know that in nature the CTM represents an out-of-phase relationship of SSTA variability between the Pacific cold tongue region and elsewhere in the tropical Pacific, and that the time series of the CTM exhibits a strong longterm trend (Figure 1). Thus, in the following, we use the Taylor diagram to evaluate the spatial pattern of the modeled CTM, and use the ratio of trends to make a comparison between the modeled and observed time series of the CTM.

Figure 5 shows the second EOF modes in SSTA over the tropical Pacific and their NPC2 time series. Most of the models are able to simulate the cooling SSTA in the eastern equatorial Pacific associated with the positive CTM well (Figure 5). However, compared with Taylor diagram analysis of the ENSO mode (Figure $3 a$ ), the spatial correlation coefficients in Figure $3 b$ are overall lower (Figure $3 \mathrm{~b})$, and the distances between the model points and the 

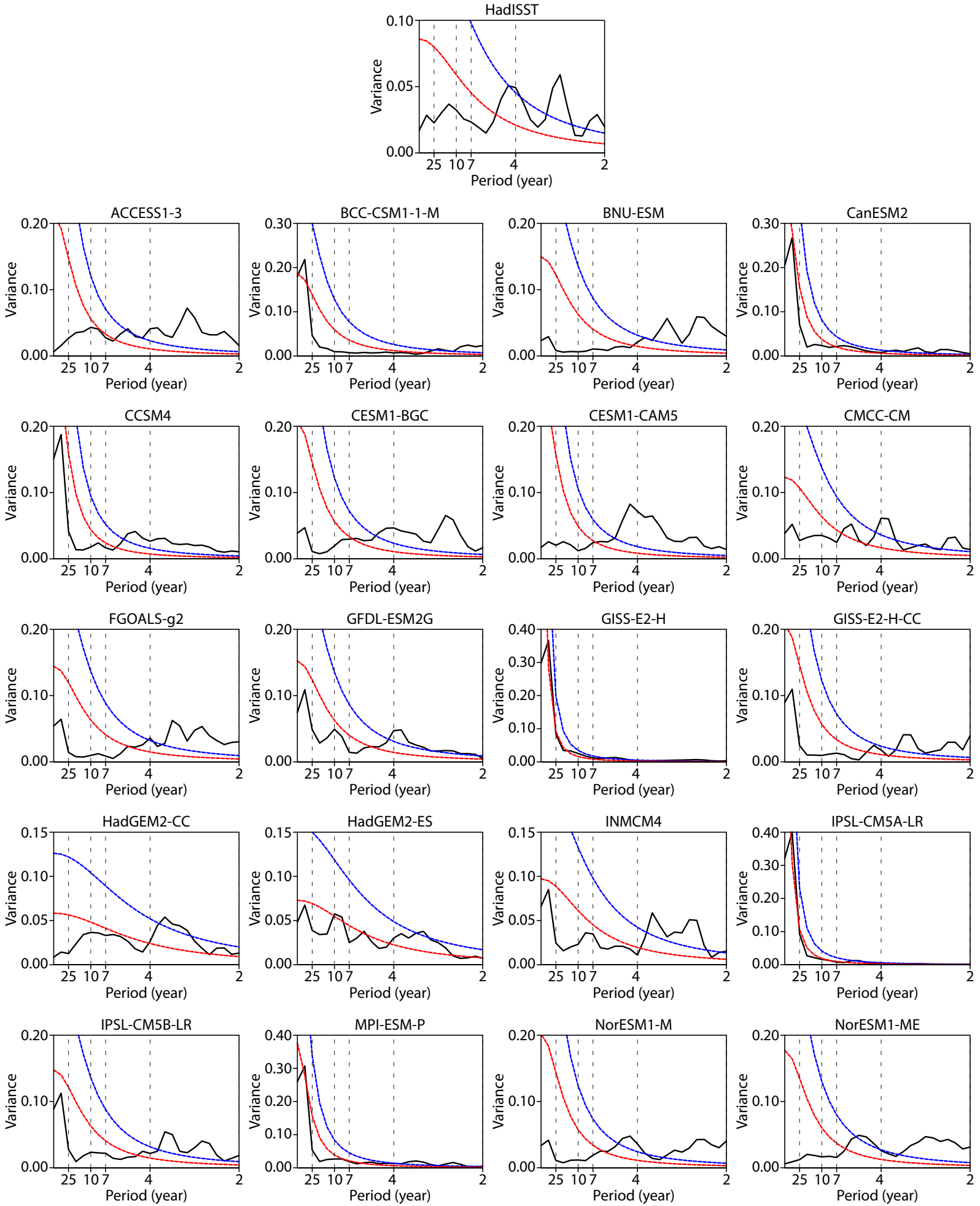

Figure 4. Power spectrum of the NPC1 derived from the HadISST1 dataset and individual CMIP5 models. The blue and red dashed lines show the $95 \%$ confidence level and the reference red noise spectra, respectively.

"REF" point (Figure 3b) are typically greater. This implies that the CMIP5 models generally provide a better simulation of the ENSO mode than of the CTM. Interestingly, eight of the models (i.e., BCC-CSM1-1-M, BNU-ESM, CCSM4, GFDL-ESM2G, GISS-E2-H, HadGEM2-ES, INMCM4, and MPI-ESM-P) mentioned above, which are not able accurately to simulate the spatial or temporal charac- teristic of the ENSO mode, are also unable to capture realistically the spatial features of the CTM. We note that these eight models have weaker spatial correlation coefficients, smaller ratios of the standard deviation, or are further from the "REF" point in comparison with the other models (Figure 3b).

Considering the simulation of the temporal features of the CTM, 

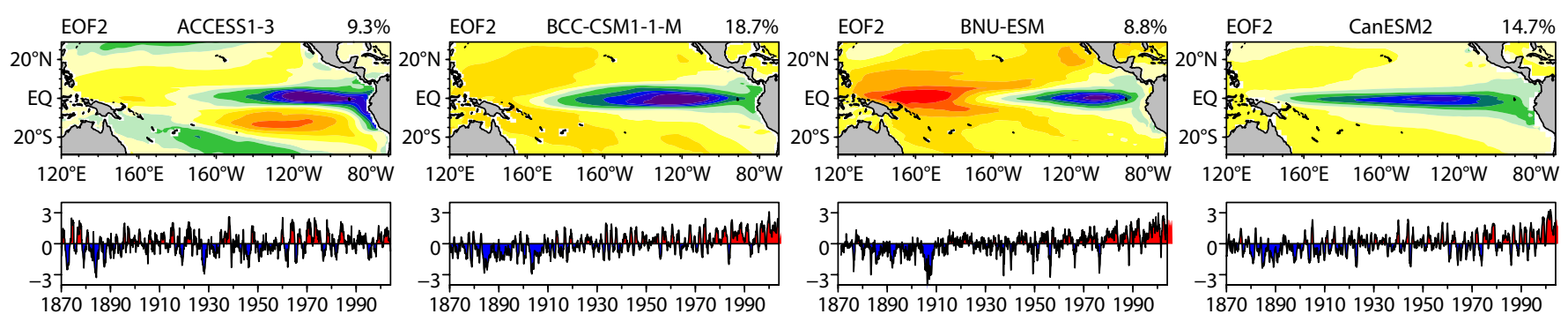

1870189019101930195019701990

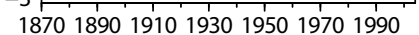

1870189019101930195019701990
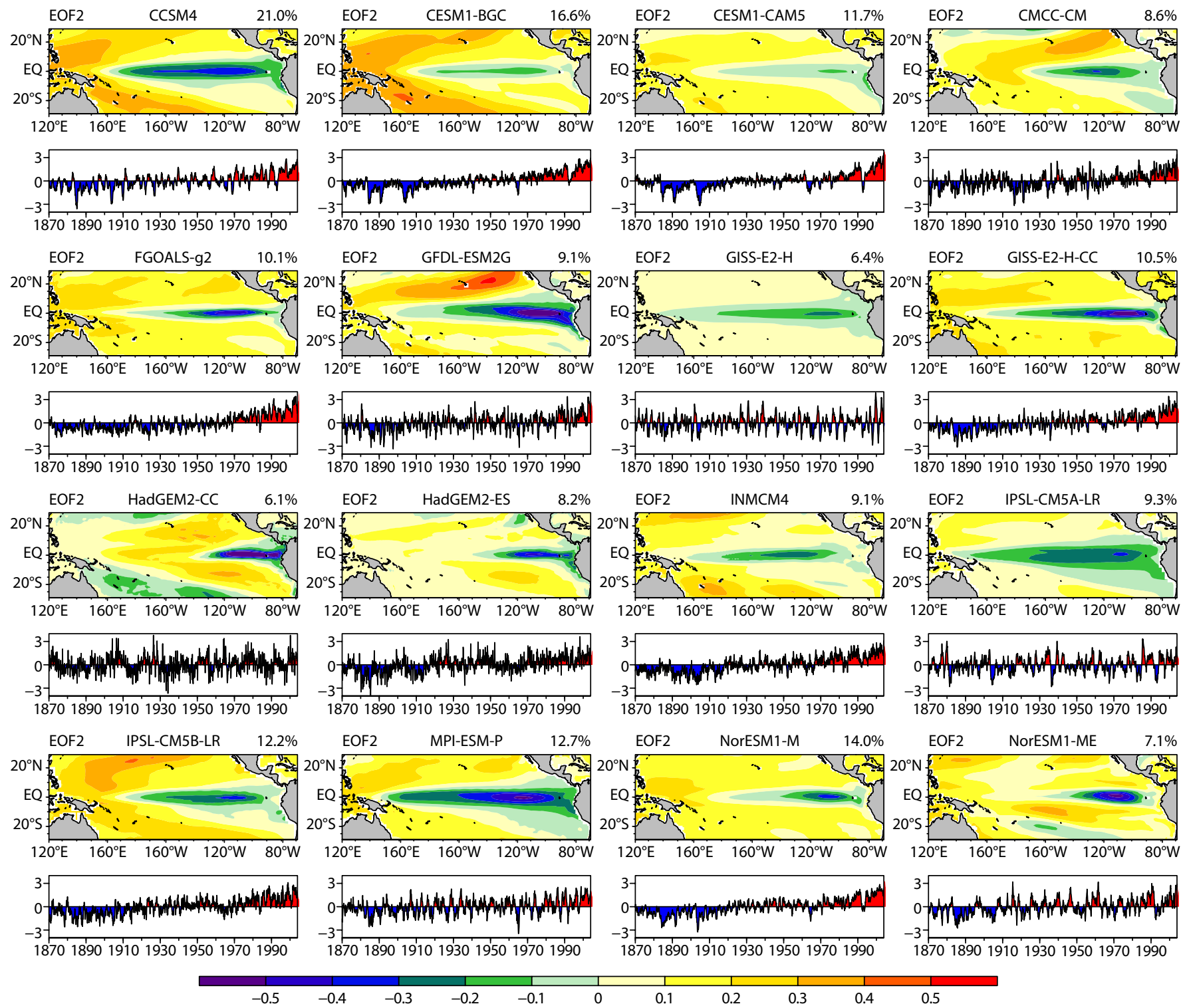

$\begin{array}{lllll}1 & 1 & 1 & 1 \\ 0.1 & 0.2 & 0.3 & 0.4\end{array}$

0.5

Figure 5. As Figure 2, but for the second EOF mode and its corresponding NPC2 time series.

we use the ratio of the simulated and observed trends of NPC2 to assess the performance of the CMIP5 models in reproducing the long-term trends in the CTM. Quantitatively, there are eight models (i.e., ACCESS1-3, CanESM2, GFDL-ESM2G, GISS-E2-H, HadGEM2CC, IPSL-CM5A-LR, MPI-ESM-P, and NorESM1-ME) whose ratios of trends are relatively weak compared with the other models (Figure 6). For four of these models in particular (i.e., ACCESS1-3, GISSE2-H, HadGEM2-CC, and IPSL-CM5A-LR), their NPC2 time series are almost dominated by the interannual signal (Figure 5). This suggests that the CTM simulated by these eight models tends to have a stronger interannual signal than that seen in the observations. In addition, of these eight models mentioned above, we also note that five (i.e., CanESM2, GFDL-ESM2G, GISS-E2-H, IPSL-CM5A-LR, and MPI-ESM-P) do not accurately reproduce the spatial or temporal characteristics of the ENSO mode. Except for these eight models, the rest of the models yield ratios of trends between the simulated and observed NPC2 time series that are generally located within a band about 0.2 wide centered on 1.0 (Figure 6). This indicates that the 10 models in the pink rectangle (Figure 6) are able to capture the observed long-term trend of the CTM. In addi- 


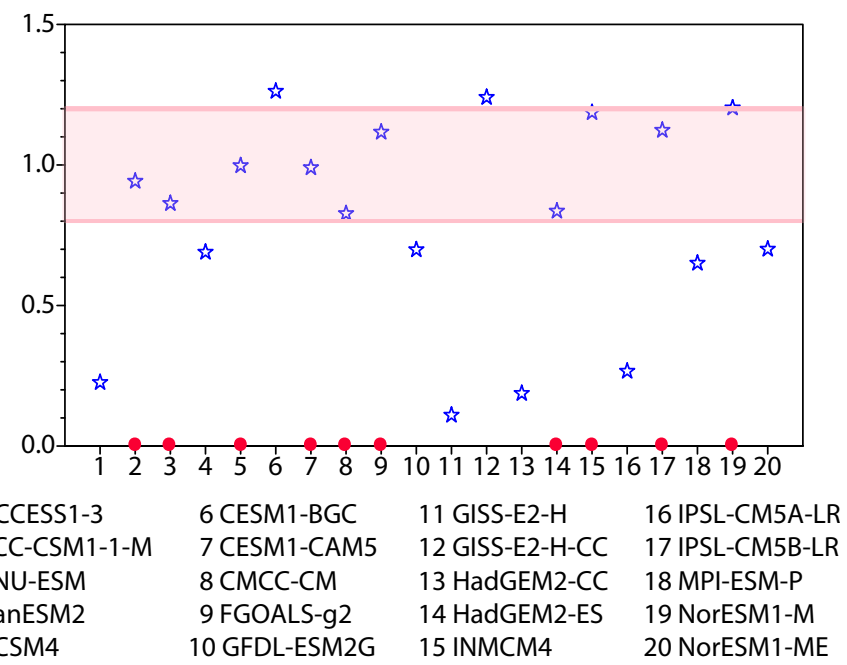

Figure 6. The ratio of the trends of the NPC2 between the historical simulations and the observations. The models in the pink rectangle are those that reasonably reproduce the observed long-term trend of the CTM when compared with the other models. The red dots indicate the numbers of those better modes. The HadISST1 dataset is used for reference.

tion, we note that in the CESM1-BGC and GISS-E2-H-CC models the long term trends are relatively strong compared with the observations (Figures 5 and 6 ).

Overall, 15 models (i.e., ACCESS1-3, BCC-CSM1-1-M, BNU-ESM, CanESM2, CCSM4, CESM1-BGC, GFDL-ESM2G, GISS-E2-H, GISS-E2H-CC, HadGEM2-CC, HadGEM2-ES, INMCM4, IPSL-CM5A-LR, MPIESM-P, and NorESM1-ME) are unable to capture satisfactorily the spatial or temporal characteristic of the CTM (Figures $3 b$ and 6). Compared with the capability, mentioned above, of the CMIP5 models in capturing the ENSO mode, our analysis suggests that if a model is not able to reproduce ENSO, then it is likely also to be unable to simulate the CTM usefully. This finding supports the suggestion of Zhang WJ et al. (2010), who emphasized that the reproduction of the CTM depends on the simulation ability of ENSO in CMIP3 models. Finally, we find that five models (i.e., CESM1CAM5, CMCC-CM, FGOALS-g2, IPSL-CM5B-LR, and NorESM1-M) yield superior results, reproducing realistic ENSO features and observed spatial characteristic and long-term trends associated with the CTM. Why the CTM is better simulated by these five models will be discussed in the following section.

\section{Performance of CMIP5 Models in Reproducing the Main Ocean Dynamical Process Associated with the CTM}

\subsection{Main Ocean Dynamical Process Associated with the CTM}

Li $Y$ et al. $(2015,2017)$ used the heat budget equation to show that "the cooling associated with the vertical advection of the anomalous temperature by the mean upwelling $\left(-\bar{w} \partial T^{\prime} / \partial z\right)$ plays a dominant role in the long-term trend of the CTM, and this is consistent with the results of DiNezio et al. (2009)". Since the CTM is well-simulated in the five models (i.e., CESM1-CAM5, CMCC-CM, FGOALS-g2, IPSL-CM5B-LR, and NorESM1-M), we expect the cooling trend of the $-\bar{w} \partial T^{\prime} / \partial z$ term to be captured by these five models.
The bottom panels in Figure 7 show a normalized time series of the $-\bar{w} \partial T^{\prime} / \partial z$ term in the eastern equatorial Pacific. It should be noted that the averaged area $\left(2^{\circ} \mathrm{S}-2^{\circ} \mathrm{N}, 140^{\circ} \mathrm{W}-80^{\circ} \mathrm{W}\right.$, and $\left.0-60 \mathrm{~m}\right)$ of the $-\bar{w} \partial T^{\prime} / \partial z$ term is the same as that of Li Y et al. (2015), who analyzed the cooling trend of the $-\bar{w} \partial T^{\prime} / \partial z$ term in the observations. Although the time series of the $-\bar{w} \partial T^{\prime} / \partial z$ term in the five models exhibit a strong interannual variability (Figure 7), they all follow a cooling trend, except in that of CESM1-CAM5 (Table 2). Note also that these trends in the five models exceed the $95 \%$ confidence level (Table 2). In addition, Compo and Sardeshmukh (2010) suggested that ENSO can be treated as noise when analyzing the long-term trend in the tropical Pacific. This indicates that ENSO may hinder our understanding of the long-term trend of the $-\bar{w} \partial T^{\prime} / \partial z$ term in CESM1-CAM5. For this reason, we first remove the ENSO signal and then perform a trend analysis on the time series of the $-\bar{W} \partial T^{\prime} / \partial z$ term generated by the five models. To remove the ENSO signal, the raw time series of the $-\bar{w} \partial T^{\prime} / \partial z$ term is regressed onto the monthly Niño 3 index, and the obtained result is then subtracted from the raw time series of the $-\bar{w} \partial T^{\prime} / \partial z$ term. After removal of the ENSO signal, the trend of the $-\bar{w} \partial T^{\prime} / \partial z$ term in CESM1-CAM5 tends towards cooling (Table 2), although this trend is statistically insignificant. For the other four models, the cooling trends of the $-\bar{w} \partial T^{\prime} / \partial z$ term without the ENSO signal are stronger than the raw trends (Table 2 ). These results suggest that the cooling trend of the $-\bar{w} \partial T^{\prime} / \partial z$ term is overall captured by these five models.

Despite there being a statistically insignificant trend of the $-\bar{w} \partial T^{\prime} / \partial z$ term time series in CESM1-CAM5, the partial correlation coefficients (PRs) without the ENSO signal (Niño 3 index) between the tropical Pacific temperature anomalies (averaged over 0-60 $\mathrm{m})$ and the $-\bar{w} \partial T^{\prime} / \partial z$ term time series correspond to strong negative correlation (multiplied by -1.0 ) in the eastern equatorial $\mathrm{Pa}$ cific, where the cooling $-\bar{w} \partial T^{\prime} / \partial z$ term is associated with the cooling temperature anomalies (Figure 7a). For the other four models, their PRs also correspond to strong negative correlation in the eastern equatorial Pacific. These spatial patterns of PR in the five 
(a) CESM1-CAM5
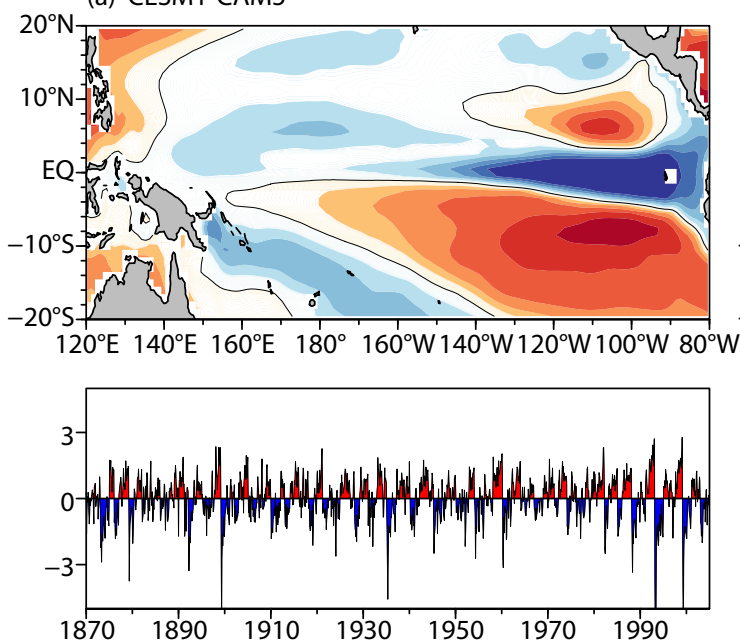

(c) FGOALS-g2
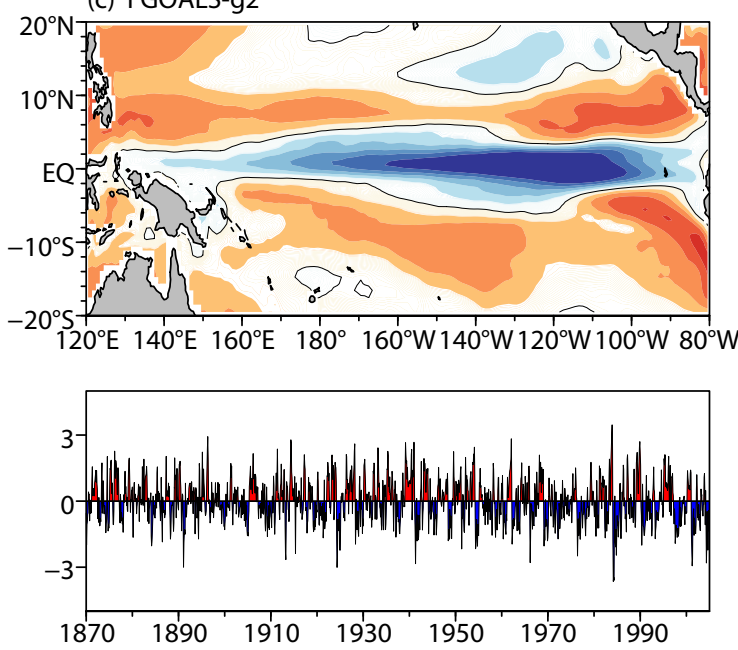

(e) NorESM1-M
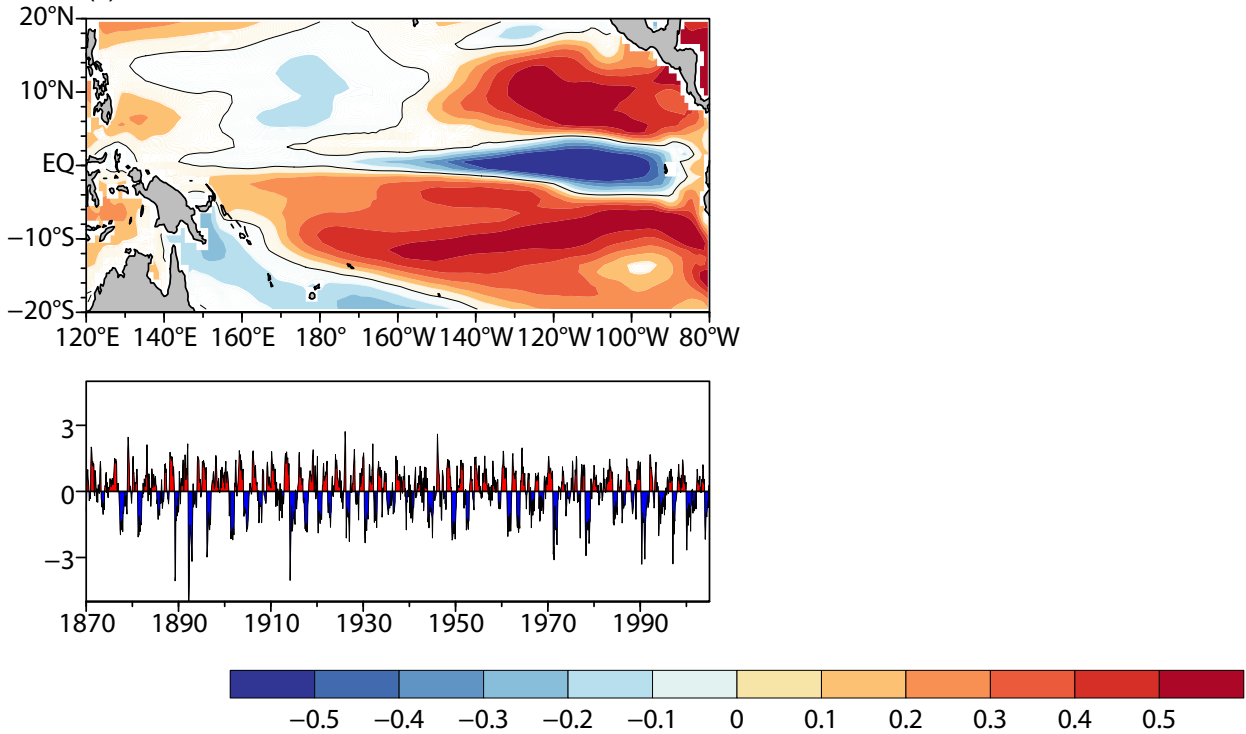

(b) CMCC-CM
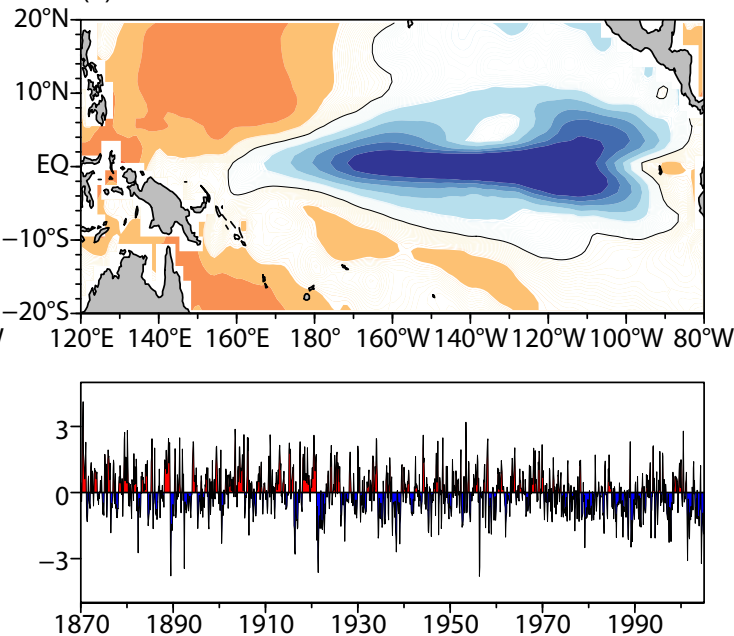

(d) IPSL-CM5B-LR
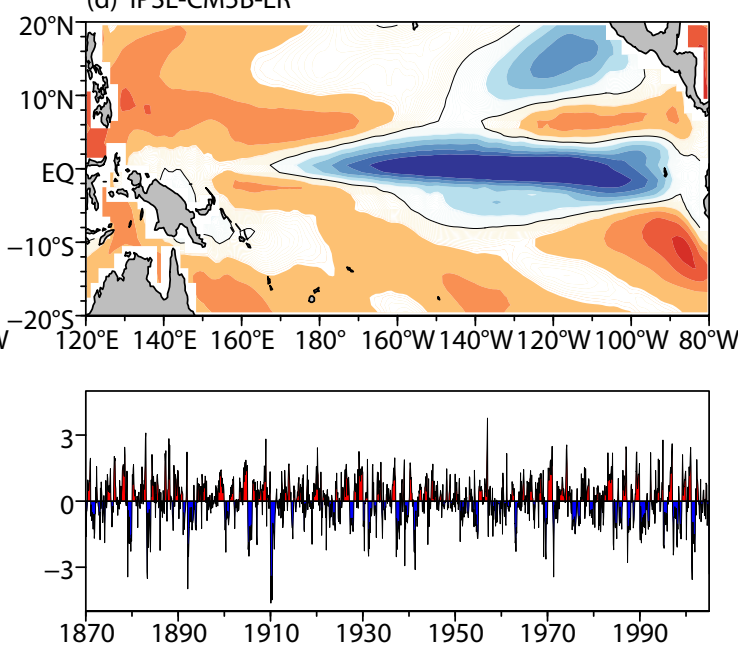
the vertical advection of the anomalous temperature by the mean upwelling in five models. The bottom panels of (a)-(e) are the corresponding normalized time series of the indices. These indices are calculated over $2^{\circ} \mathrm{S}-2^{\circ} \mathrm{N}, 140^{\circ} \mathrm{W}-80^{\circ} \mathrm{W}$, and $0-60 \mathrm{~m}$. The historical simulations are from CESM-CAM5, CMCC-CM, FGOALS-g2, IPSL-CM5B-LR, and NorESM1-M. Shading indicates statistical significance at the $99.9 \%$ confidence level, and the thin black contour denotes the zero line. To allow a direct comparison, the PR patterns in (a)-(e) are multiplied by -1.0 . 
Table 2. The 100-year trends of the vertical advection of the anomalous temperature by the mean upwelling and the vertical temperature gradient for the time series. The first and second columns respectively show the raw trends and the trends without the ENSO signal in the five models. These indices were calculated over $2^{\circ} \mathrm{S}-2^{\circ} \mathrm{N}, 140^{\circ} \mathrm{W}-80^{\circ} \mathrm{W}$, and $0-60 \mathrm{~m}^{\mathrm{a}}$

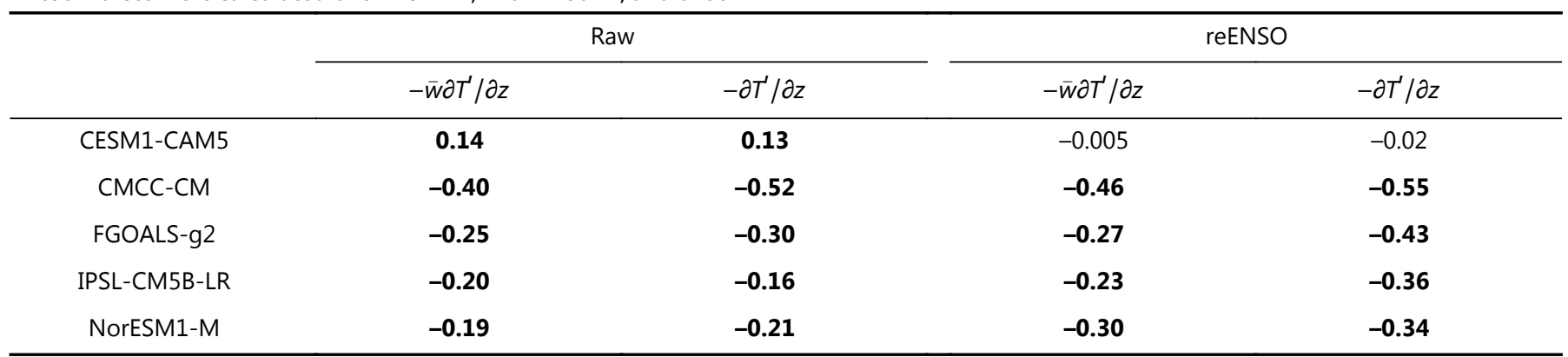

aBold values indicate significant at the 95\% confidence level (nonparametric Mann-Kendall test).

models (Figure 7) are similar to the spatial pattern of the positive CTM (Figure 1), which shows the cooling SSTA in the tropical Pacific cold tongue region. The above results indicate that the five models generally simulate the main ocean dynamical process associated with the CTM.

The analysis above motivated us to examine further why these five models are able to capture the main ocean dynamical process associated with the CTM. Li Y et al. $(2015,2017)$ emphasized that "the cooling term $-\bar{w} \partial T^{\prime} / \partial z$ is controlled by the decreasing vertical gradient of temperature anomalies $\left(\partial T^{\prime} / \partial z\right)^{\prime \prime}$. Thus, the question becomes How well do the five models reproduce the decreasing trend of the $\partial T^{\prime} / \partial z$ term? To address this issue, in the following section we will investigate the trend of the $\partial T^{\prime} / \partial z$ term and its associated sea temperature pattern in the five models.

\subsection{Vertical Temperature Gradient in the Eastern Equatorial Pacific}

Figure 8 shows, for the five models (i.e., CESM1-CAM5, CMCC-CM, FGOALS-g2, IPSL-CM5B-LR, and NorESM1-M), their normalized time series of the $\partial T^{\prime} / \partial z$ term and their corresponding PR patterns. After removal of the ENSO signal, the PRs between the tropical Pacific temperature anomalies and the $\partial T^{\prime} / \partial z$ term all tend towards a significantly strong negative correlation (multiplied by -1.0 ) in the eastern equatorial Pacific, where the decreasing $\partial T^{\prime} / \partial z$ term is associated with the cooling temperature anomalies (Figure 8). Meanwhile, in four of the five models (i.e., except for CESM1CAM5; Table 2), the time series of the $\partial T^{\prime} / \partial z$ term show a decreasing trend. After excluding the interference related to the ENSO signal, the time series of the $\partial T^{\prime} / \partial z$ term also follows a decreasing trend in CESM1-CAM5, although this trend is statistically insignificant (Table 2). For the CESM1-CAM5 simulation without the ENSO signal, this insignificant decreasing trend of the $\partial T^{\prime} / \partial z$ term could induce the weak cooling trend of the $-\bar{w} \partial T^{\prime} / \partial z$ term in the eastern equatorial Pacific (Table 2). In addition, the decreasing trends of the $\partial T^{\prime} / \partial z$ term without the ENSO signal are stronger relative to their raw trends in all five models (Table 2). These simulated results are similar to the observed results of Li Y et al. (2017). Overall, these results suggest that the five models generally reproduce the decreasing $\partial T^{\prime} / \partial z$ term in the eastern equatorial Pacific.

To further clarify the decreasing $\partial T^{\prime} / \partial z$ term in the eastern equatorial Pacific, the trends of the $\partial T^{\prime} / \partial z$ term are calculated from the surface to thermocline (about $60 \mathrm{~m}$ ). As shown in Figure 9, the raw trends of the $\partial T^{\prime} / \partial z$ term from the surface to thermocline are decreasing in all five models except CESM1-CAM5. After removal of the ENSO signal, the decreasing trends in these five models are generally stronger than the raw trends from the surface to $40 \mathrm{~m}$ (Figure 9). Note that the trends in the $\partial T^{\prime} / \partial z$ term without the ENSO signal are insignificant in CESM1-CAM5, although they do decrease above $50 \mathrm{~m}$. Aside from CESM1-CAM5, the decreasing trends without the ENSO signal above $40 \mathrm{~m}$ are statistically significant (Figure 9). These results are consistent with the above analysis that shows the long-term trend of the time series of the $\partial T^{\prime} / \partial z$ term without the ENSO signal (Table 2).

We also analyze the long-term trends of the subsurface temperature of the eastern equatorial Pacific in the five models (Figure 10). The raw trends above thermocline in these five models are generally warming (Figure 10). However, the raw trends of sea temperature in four of the models (i.e., CMCC-CM, FGOALS-g2, IPSLCM5B-LR, and NorESM1-M in Figure 10) are that warming decreases with increased depth. This pattern induces the decreasing trend of the $\partial T^{\prime} / \partial z$ term above the thermocline in these four models (Figure 9). Interestingly, when the ENSO signal is removed, the subsurface temperature of the eastern equatorial Pacific in all five models shows a cooling trend (Figure 10). This simulated result is consistent with the observed result of Li Y et al. (2017), who found a cooling trend of subsurface temperature in the eastern equatorial Pacific. Moreover, the trends above $40 \mathrm{~m}$ without the ENSO signal are statistically significant and are cooling at all depths in all five models (Figure 10), and contribute to the decreasing trend in the $\partial T^{\prime} / \partial z$ term without the ENSO signal above $40 \mathrm{~m}$ (Figure 9). Overall, these results indicate that the five models could capture the main ocean dynamical process associated with the CTM, namely, the decreasing trend of the $\partial T^{\prime} / \partial z$ term and the cooling trend of the $-\bar{w} \partial T^{\prime} / \partial z$ term.

\section{Discussion and Conclusions}

This study used historical simulations generated by 20 CMIP5 models to test their ability to simulate the CTM. Using Taylor diagrams, the power spectra, and the ratio of the trend in normalized principal components (NPC2) between the model simulations and the observations, we evaluated the spatial and temporal characteristics of the ENSO mode and CTM in these 20 models. In general, we find that models unable accurately to simulate the 
(a) CESM1-CAM5
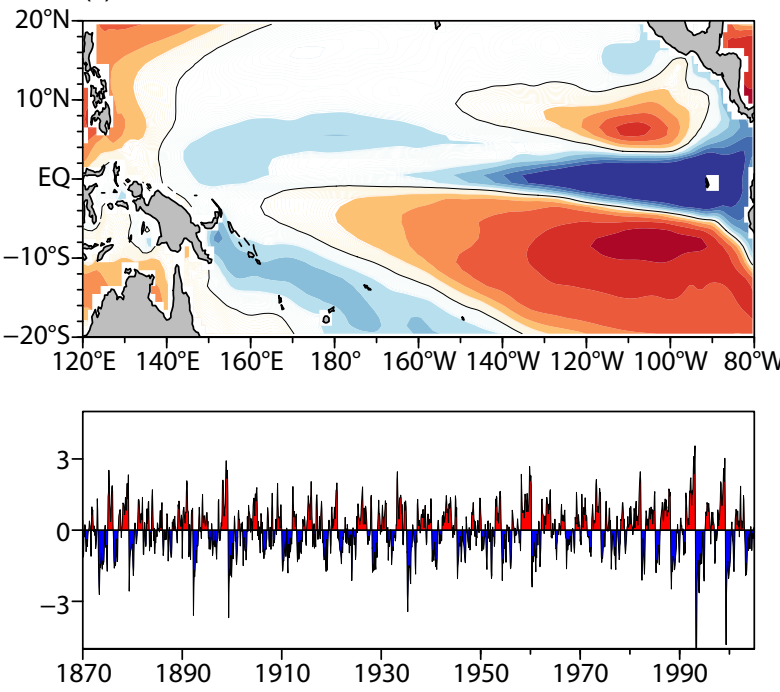

(c) FGOALS-g2
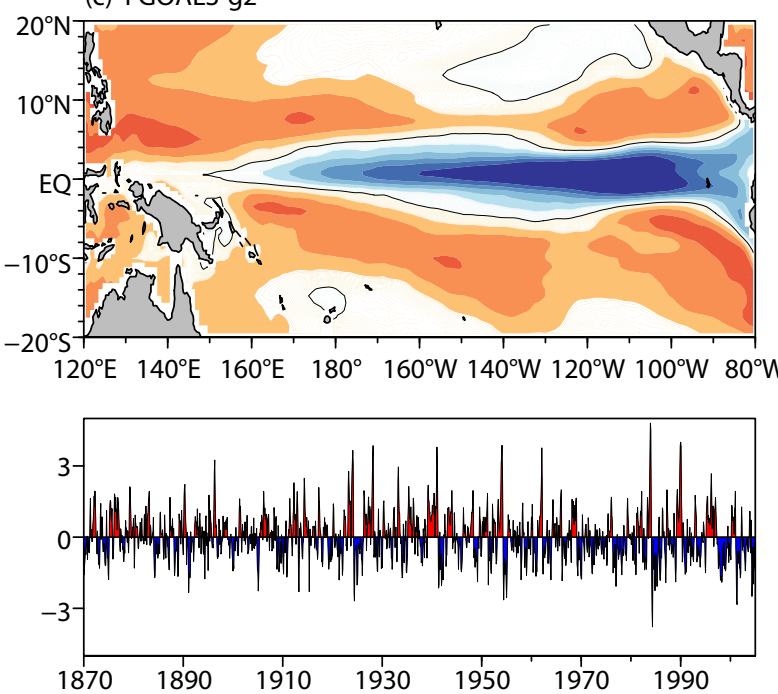

(e) NorESM1-M
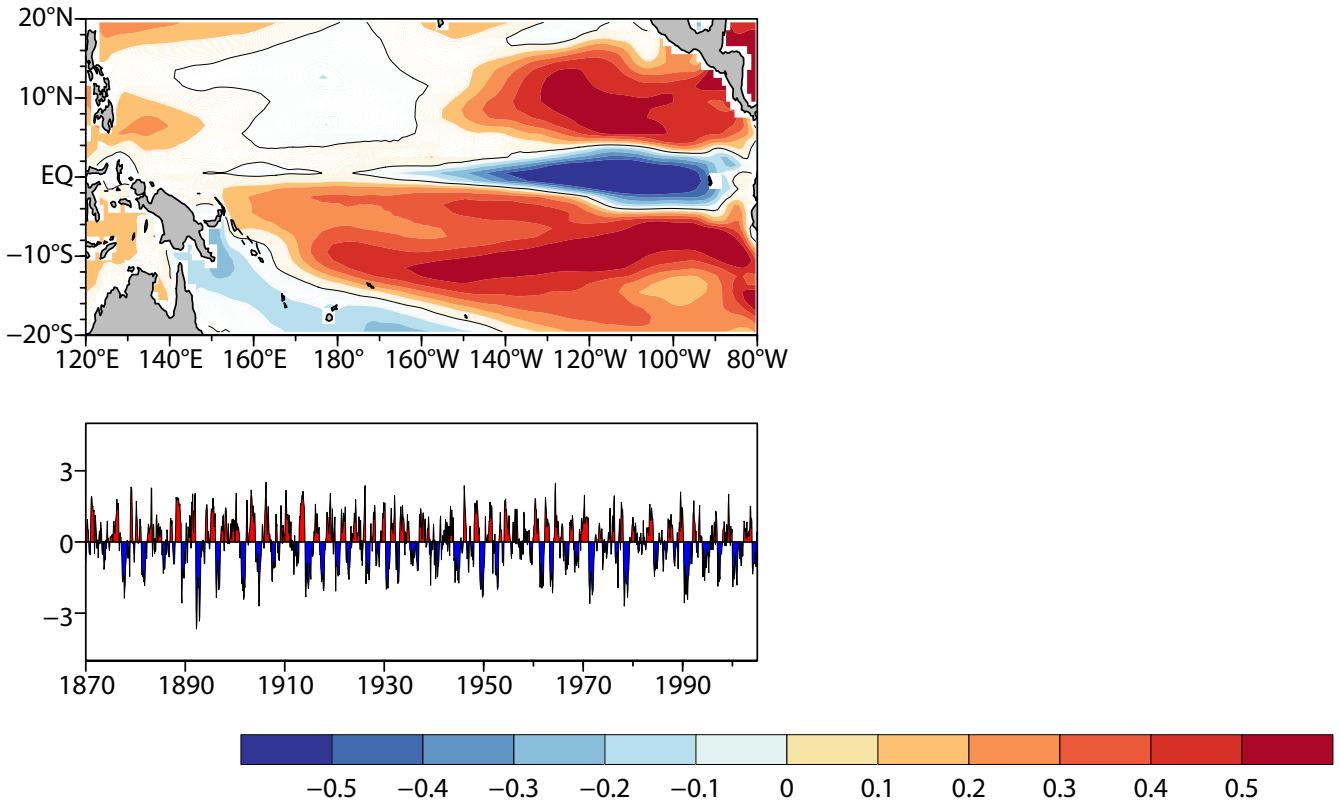

(b) CMCC-CM
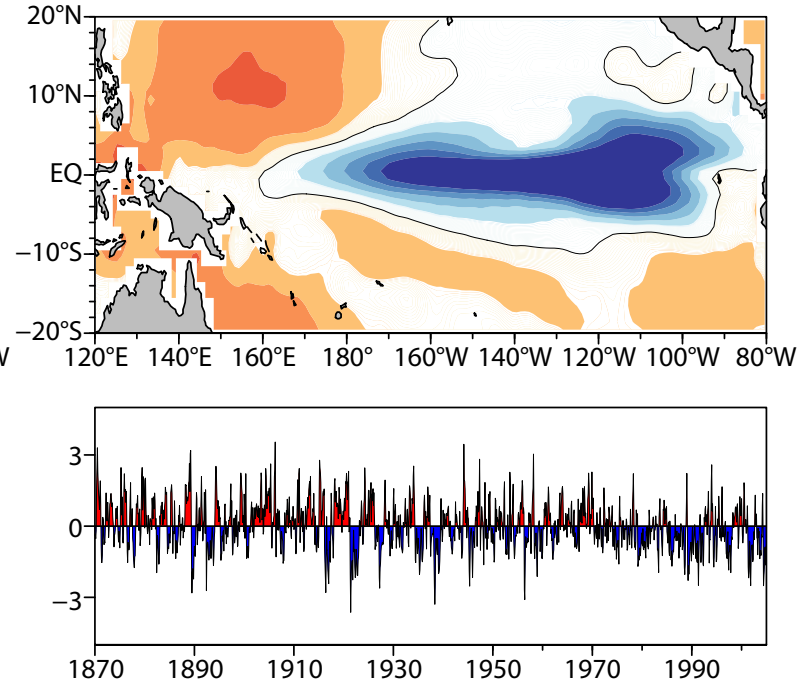

(d) IPSL-CM5B-LR
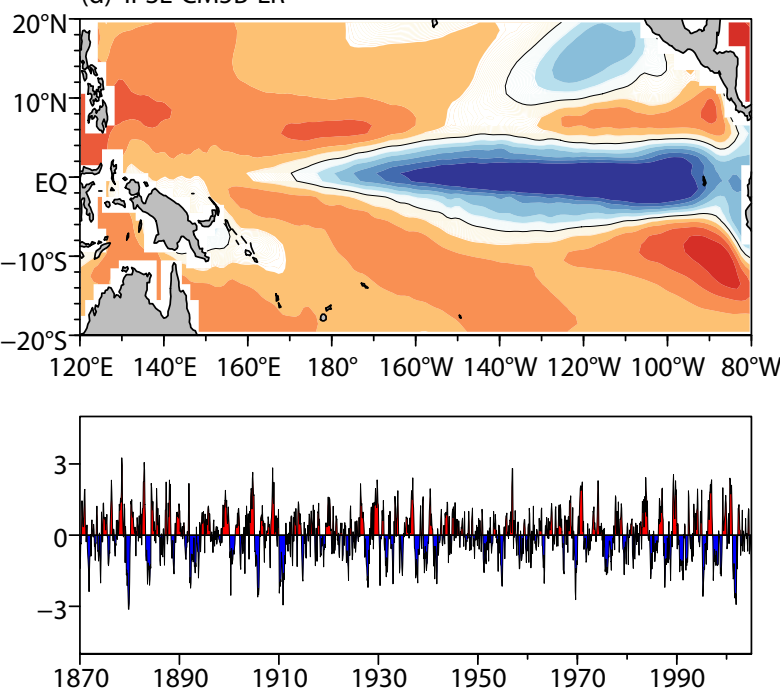
(a) CESM1-CAM5

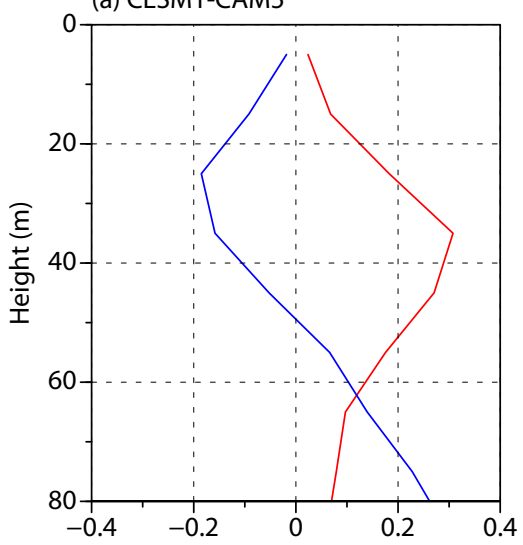

(d) IPSL-CM5B-LR

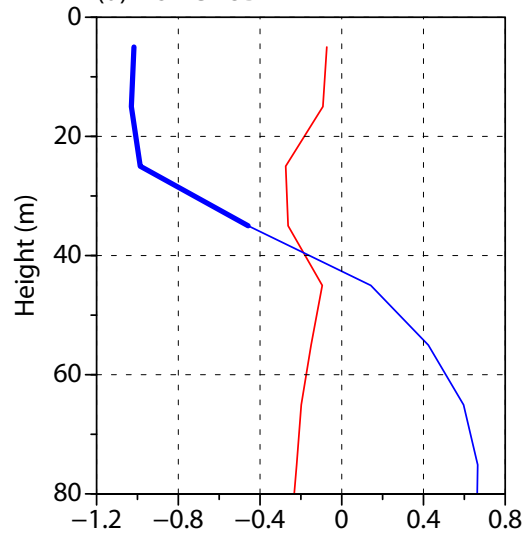

(b) CMCC-CM

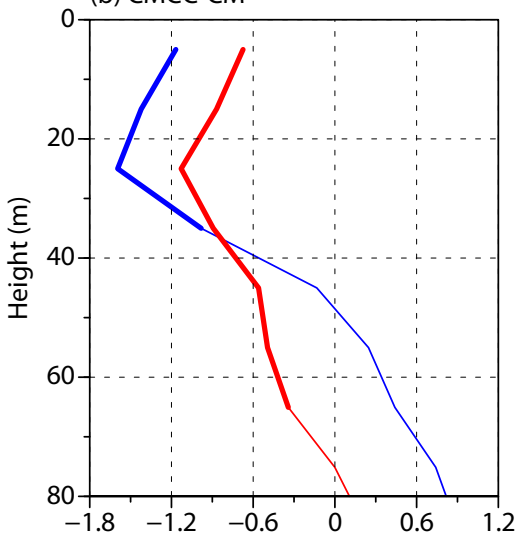

(e) NorESM1-M

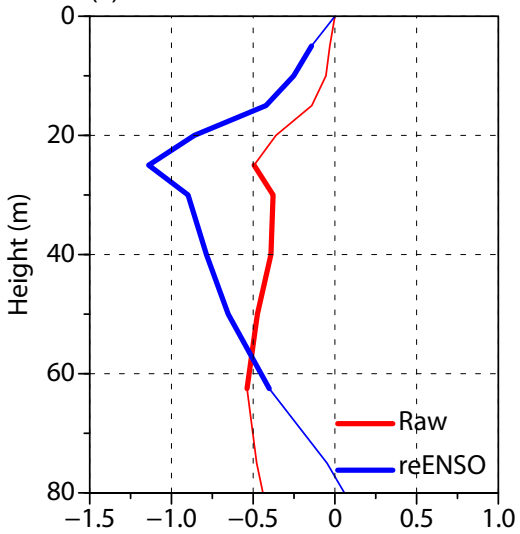

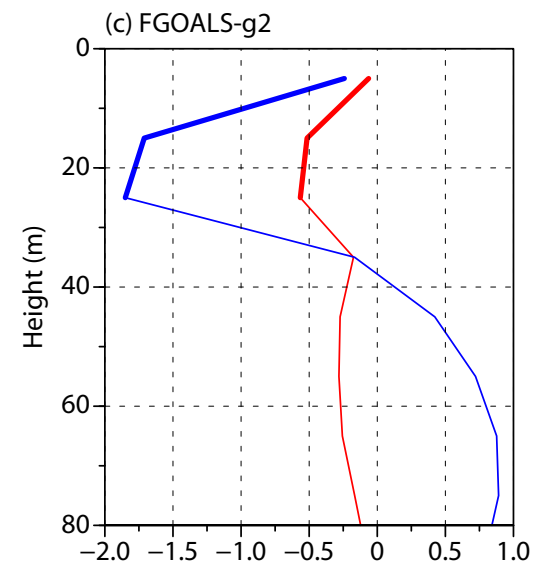

Figure 9. The trends (in $10^{-2}{ }^{\circ} \mathrm{C} / \mathrm{m}$ per 100 years) of vertical temperature gradient over the eastern equatorial Pacific $\left(2^{\circ} \mathrm{S}-2^{\circ} \mathrm{N}, 140^{\circ} \mathrm{W}-80^{\circ} \mathrm{W}\right)$. The red and blue lines represent the raw trend and removed ENSO signal trend, respectively. Thicker lines indicate significant at the $95 \%$ confidence level (nonparametric Mann-Kendall test).

ENSO feature in the EOF1 mode of the tropical Pacific are also unable to reproduce usefully the observed spatial pattern and longterm trend associated with the CTM that appears in EOF2. Note that eleven of the models (i.e., BCC-CSM1-1-M, BNU-ESM, CanESM2, CCSM4, GFDL-ESM2G, GISS-E2-H, GISS-E2-H-CC, HadGEM2-ES, INMCM4, IPSL-CM5A-LR, and MPI-ESM-P) could not accurately simulate the spatial characteristic of ENSO and also could not reproduce the CTM well. Of the rest of the models, some are able to reproduce the ENSO features, but could not capture effectively the spatial characteristics or the long-term trend of the CTM. For instance, the models ACCESS1-3, HadGEM2-CC, and NorESM1-ME are unable to reproduce the spatial pattern of the CTM (Figure 3b), and the long-term trend of the CTM simulated by CESM1-BGC is too strong, compared with the observations (Figure 6). Finally, five models (i.e., CESM1-CAM5, CMCC-CM, FGOALSg2, IPSL-CM5B-LR, and NorESM1-M) are capable of capturing with reasonable accuracy the spatial pattern and long-term trend of the CTM. Note that other models are unable to simulate the CTM, which may be related to tropical biases in these CMIP5 models (Kug et al., 2012; Bellenger et al., 2014). In addition, based on the main ocean dynamical process associated with the CTM, the diversity among models in representing the mean upwelling of the eastern equatorial Pacific (Li G and Xie SP, 2012; Li Y et al., 2015) may induce the inter-model difference in the CTM (Figure 5).
Regarding the performance of CMIP5 models in reproducing the main ocean dynamical process associated with the CTM, we find that five models (i.e., CESM1-CAM5, CMCC-CM, FGOALS-g2, IPSLCM5B-LR, and NorESM1-M) generally simulate the main ocean dynamical process associated with the CTM. In four of these five models (i.e., not in CESM1-CAM5; Table 2), the time series of the $-\bar{W} \partial T^{\prime} / \partial z$ term in the eastern equatorial Pacific shows a cooling trend. After removal of the ENSO signal, however, all five models yield a cooling trend for the $-\bar{w} \partial T^{\prime} / \partial z$ term in the eastern equatorial Pacific (Table 2). These results suggest that the five models generally reproduce the main ocean dynamical process associated with the CTM and thus capture the spatial pattern and longterm trend of the CTM.

The cooling trend of the $-\bar{w} \partial T^{\prime} / \partial z$ term is controlled by the decreasing trend of the $\partial T^{\prime} / \partial z$ term. We also find a decreasing trend in the $\partial T^{\prime} / \partial z$ term after removing the ENSO signal in the eastern equatorial Pacific (Table 2). These decreasing trends are all significant, except for CESM1-CAM5 (Table 2). In CESM1-CAM5, the insignificant cooling trend of the $-\bar{w} \partial T^{\prime} / \partial z$ term results from the insignificant decreasing trend of the $\partial T^{\prime} / \partial z$ term (Table 2). Note that the decreasing $\partial T^{\prime} / \partial z$ term is dominated by the change in subsurface temperature, which cools with increased depth in the eastern equatorial Pacific (Figure 10).

This study has briefly assessed the representation of the observed 

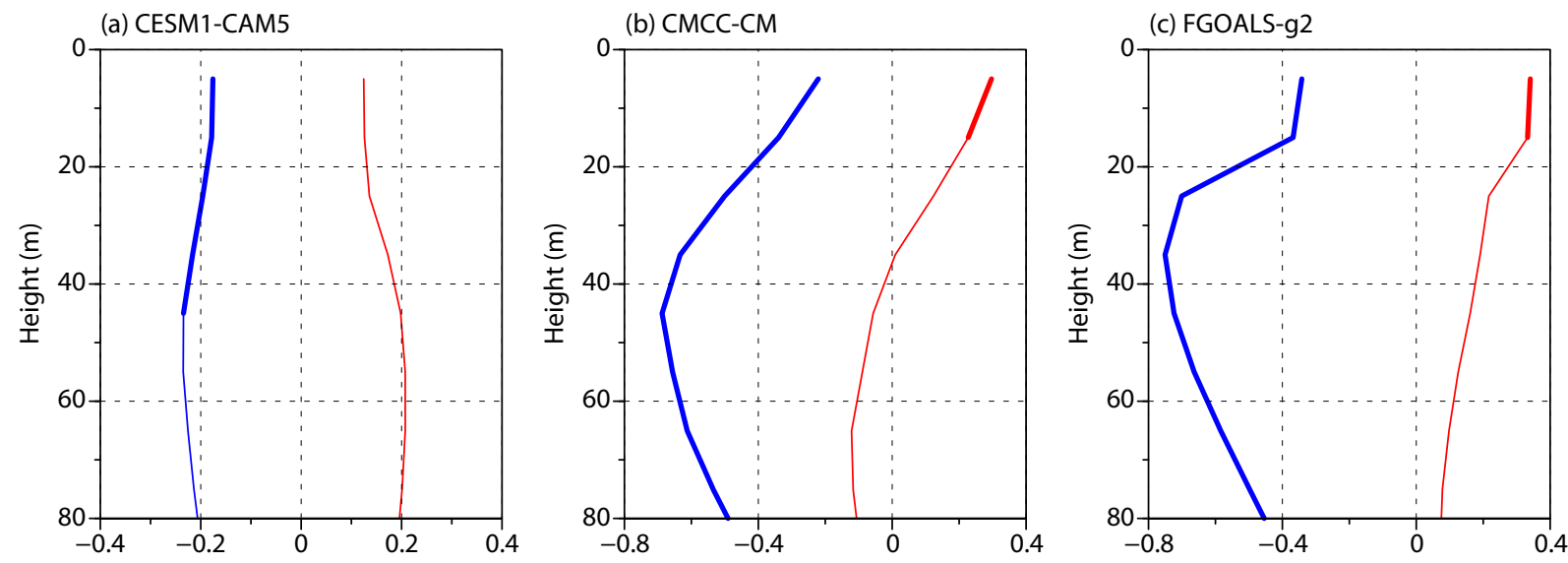

(d) IPSL-CM5B-LR
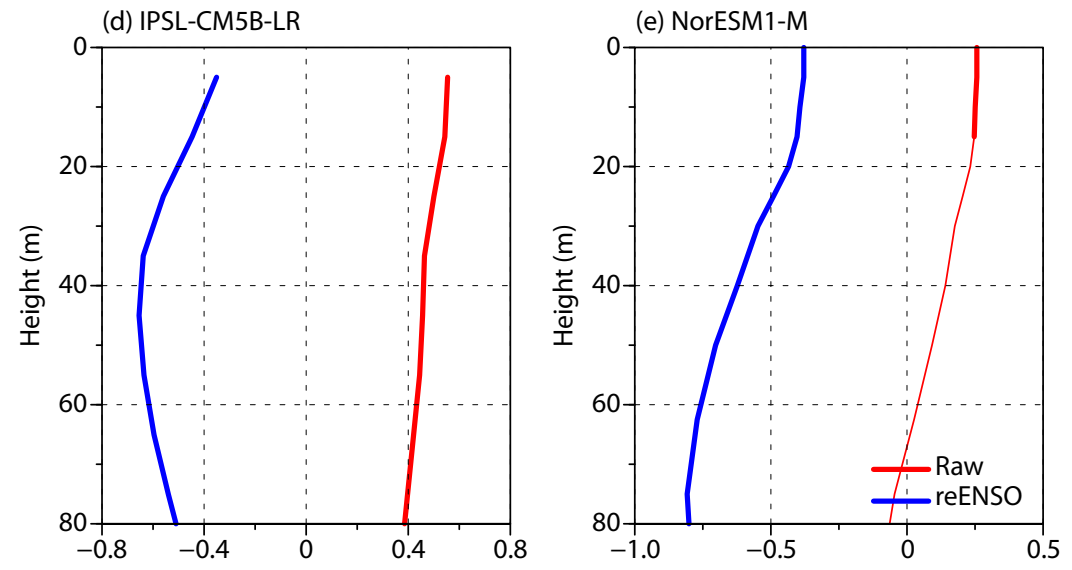

Figure 10. As Figure 9 , but for the trends (in ${ }^{\circ} \mathrm{C}$ per 100 years) of subsurface temperature.

CTM in the 20 CMIP5 models, and provides a new insight into the simulation of the dynamics of the tropical Pacific. However, the following questions remain. Why are some CMIP5 models unable to reasonably reproduce the CTM? How well do these models simulate the main ocean dynamical process associated with the CTM? Furthermore, although the CMIP5 models are demonstrably improved compared to the CMIP3 models, has there been corresponding improvement in their simulation of the CTM? If so, what is the cause of the improvement(s)? We will address these important questions in future studies.

\section{Acknowledgments}

This work was supported jointly by the National Key Research and Development Program on Monitoring, Early Warning and Prevention of Major Natural Disaster (2018YFC1506006), the National Natural Science Foundation of China Project (41805054, $41875108,41775072,41705065)$, and the SOA International Cooperation Program on Global Change and Air-Sea Interactions (GASI-IPOVAI-03). We acknowledge the modeling groups listed in Table 1 for providing the model output for analysis, the WCRP's Working Group on Coupled Modeling (WGCM) for organizing the CMIP, and the Earth System Grid Federation (ESGF) for supporting the model data archive (http://cmip-pcmdi.IInl.gov/cmip5). The HadISST1 dataset was obtained from the UK Met Office Hadley Centre and can be downloaded from http://www.metoffice.gov. uk/hadobs/hadisst/data/download.html.

\section{References}

Ashok, K., Behera, S. K., Rao, S. A., Weng, H. Y., and Yamagata, T. (2007). El Niño Modoki and its possible teleconnection. J. Geophys. Res. Oceans, 112(C11), C11007. https://doi.org/10.1029/2006JC003798

Bellenger, H., Guilyardi, E., Leloup, J., Lengaigne, M., and Vialard, J. (2014). ENSO representation in climate models: from CMIP3 to CMIP5. Climate Dyn., 42(78), 1999-2018. https://doi.org/10.1007/s00382-013-1783-z

Cane, M. A., Clement, A. C., Kaplan, A., Kushnir, Y., Pozdnyakov, D., Seager, R., Zebiak, S. E., and Murtugudde, R. (1997). Twentieth-century sea surface temperature trends. Science, 275(5302), 957-960. https://doi.org/10.1126/science.275.5302.957

Capotondi, A., Wittenberg, A. T., Newman, M., Di Lorenzo, E., Yu, J. Y., Braconnot, P., Cole, J., Dewitte, B., Giese, B., ... Yeh, S. W. (2015). Understanding ENSO diversity. Bull. Am. Meteor. Soc., 96(6), 921-938. https://doi.org/10.1175/BAMS-D-13-00117.1

Coats, S., and Karnauskas, K. B. (2017). Are simulated and observed twentieth century tropical Pacific sea surface temperature trends significant relative to internal variability?. Geophys. Res. Lett., 44(19), 9928-9937. https://doi.org/10.1002/2017GL074622

Coats, S., and Karnauskas, K. B. (2018). A role for the Equatorial Undercurrent in the ocean dynamical thermostat. J. Climate, 31(16), 6245-6261. https://doi.org/10.1175/JCLI-D-17-0513.1

Collins, M., An, S. I., Cai, W. J., Ganachaud, A., Guilyardi, E., Jin, F. F., Jochum, M., Lengaigne, M., Power, S., ... Wittenberg, A. (2010). The impact of global warming on the tropical Pacific ocean and El Niño. Nat. Geosci., 3(6), 391-397. https://doi.org/10.1038/ngeo868

Compo, G. P., and Sardeshmukh, P. D. (2010). Removing ENSO-Related Variations from the Climate Record. J. Climate, 23(8), 1957-1978. https://doi.org/10.1175/2009JCLI2735.1

Deser, C., Alexander, M. A., Xie, S. P., and Phillips, A. S. (2009). Sea surface temperature variability: Patterns and mechanisms. Annu. Rev. Mar. Sci., 2, 
115-143. https://doi.org/10.1146/annurev-marine-120408-151453 DiNezio, P. N., Clement, A. C., Vecchi, G. A., Soden, B. J., Kirtman, B. P., and Lee, S. K. (2009). Climate response of the equatorial Pacific to global warming. J. Climate, 22(18), 4873-4892. https://doi.org/10.1175/2009JCLI2982.1

Drenkard, E. J., and Karnauskas, K. B. (2014). Strengthening of the Pacific equatorial undercurrent in the SODA reanalysis: mechanisms, ocean dynamics, and implications. J. Climate, 27(6), 2405-2416. https://doi.org/10.1175/jcli-d-13-00359.1

Duan, W. S., Tian, B., and Xu, H. (2014). Simulations of two types of El Niño events by an optimal forcing vector approach. Climate Dyn., 43(5-6), 1677-1692. https://doi.org/10.1007/s00382-013-1993-4

Funk, C. C., and Hoell, A. (2015). The leading mode of observed and CMIP5 ENSO-residual sea surface temperatures and associated changes in IndoPacific climate. J. Climate, 28(11), 4309-4329. https://doi.org/10.1175/JCLID-14-00334.1

Jiang, N., and Zhu, C. W. (2018). Asymmetric changes of ENSO diversity modulated by the cold tongue mode under recent global warming. Geophys. Res. Lett., 45(22), 12506-512513. https://doi.org/10.1029/2018GL079494

Karnauskas, K. B., Seager R., Kaplan A., Kushnir Y., and Cane M. A. (2009). Observed strengthening of the zonal sea surface temperature gradient across the equatorial Pacific Ocean. J. Climate, 22(16), 4316-4321. https://doi.org/10.1175/2009JCLI2936.1

Karnauskas, K. B. (2013). Can we distinguish canonical El Niño from Modoki?. Geophys. Res. Lett., 40(19), 5246-5251. https://doi.org/10.1002/grl.51007

Kim, S. T., and Yu, J. Y. (2012). The two types of ENSO in CMIP5 models. Geophys. Res. Lett., 39(11), L11704. https://doi.org/10.1029/2012GL052006

Kug, J. S., Ham, Y. G., Lee, J. Y., and Jin, F. F. (2012). Improved simulation of two types of El Niño in CMIP5 models. Environ. Res. Lett., 7(3), 034002. https://doi.org/10.1088/1748-9326/7/3/034002

Lemmon, D. E., and Karnauskas, K. B. (2019). A metric for quantifying El Niño pattern diversity with implications for ENSO-mean state interaction. Climate Dyn., 52(12), 7511-7523. https://doi.org/10.1007/s00382-018-4194-3

L'Heureux, M. L., Lee, S., and Lyon, B. (2013). Recent multidecadal strengthening of the Walker circulation across the tropical Pacific. Nat. Climate Change, 3(6), 571-576. https://doi.org/10.1038/nclimate1840

Li, G., and Xie, S. P. (2012). Origins of tropical-wide SST biases in CMIP multimodel ensembles. Geophys. Res. Lett., 39(22), L22703. https://doi.org/10.1029/2012GL053777

Li, J. P., Ren, R. C., Qi, Y. Q., Wang, F. M., Lu, R. Y., Zhang, P. Q., Jiang, Z. H., Duan, W. S., Yu, F., and Yang, Y. Z. (2013). Progress in air-land-sea interactions in Asia and their role in global and Asian climate change. Chin. J. Atmos. Sci. (in Chinese), 37(2), 518-538. https://doi.org/10.3878/j.issn.10069895.2012.12322

Li, Y., Li, J. P., Zhang, W. J., Zhao, X., Xie, F., and Zheng, F. (2015). Ocean dynamical processes associated with the tropical Pacific cold tongue mode. J. Geophys. Res. Oceans, 120(9), 6419-6435. https://doi.org/10.1002/2015JC010814

Li, Y., Li, J. P., Zhang, W. J., Chen, Q. L., Feng, J., Zheng, F., Wang, W., and Zhou, X. (2017). Impacts of the tropical Pacific cold tongue mode on ENSO diversity under global warming. J. Geophys. Res. Oceans, 122(11), 8524-8542. https://doi.org/10.1002/2017JC013052

Li, Y., Chen, Q. L., Liu, X. R., Li, J. P., Xing, N., Xie, F., Feng, J., Zhou, X., Cai, H. K., and Wang, Z. L. (2019). Long-term trend of the tropical Pacific trade winds under global warming and its causes. J. Geophys. Res. Oceans, 124(4), 2626-2640. https://doi.org/10.1029/2018JC014603

Lin, R. P., Zheng, F., and Dong, X. (2018). ENSO frequency asymmetry and the Pacific Decadal Oscillation in observations and 19 CMIP5 models. Adv. Atmos. Sci., 35(5), 495-506. https://doi.org/10.1007/s00376-017-7133-z

Newman, M., Alexander, M. A., Ault, T. R., Cobb, K. M., Deser, C., Di Lorenzo, E., Mantua, N. J., Miller, A. J., Minobe, S., ... Smith, C. A. (2016). The Pacific decadal oscillation, revisited. J. Climate, 29(12), 4399-4427. https://doi.org/10.1175/JCLI-D-15-0508.1

Rayner, N. A., Parker, D. E., Horton, E. B., Folland, C. K., Alexander, L. V., Rowell, D. P., Kent, E. C., and Kaplan, A. (2003). Global analyses of sea surface temperature, sea ice, and night marine air temperature since the late nineteenth century. J. Geophys. Res. Atmos., 108(D14), 4407. https://doi.org/10.1029/2002JD002670

Ren, H. L., and Jin, F. F. (2013). Recharge oscillator mechanisms in two types of ENSO. J. Climate, 26(17), 6506-6523. https://doi.org/10.1175/JCLI-D-1200601.1

Ren, H. L., Jin, F. F., Stuecker, M. F., and Xie, R. H. (2013). ENSO regime change since the late $1970 \mathrm{~s}$ as manifested by two types of ENSO. J. Meteor. Soc. Japan. Ser. II, 91(6), 835-842. https://doi.org/10.2151/jmsj.2013-608

Ren, H. L., Jin, F. F., Tian, B., and Scaife, A. A. (2016a). Distinct persistence barriers in two types of ENSO. Geophys. Res. Lett., 43(20), 10973-10979. https://doi.org/10.1002/2016GL071015

Ren, H. L., Zuo, J. Q., Jin, F.-F., and Stuecker, M. F. (2016b). ENSO and annual cycle interaction: the combination mode representation in CMIP5 models. Climate Dyn., 46(11-12), 3753-3765. https://doi.org/10.1007/s00382-0152802-z

Sen, P. K. (1968). Estimates of the regression coefficient based on Kendall's tau. J. Am. Stat. Assoc., 63(324), 1379-1389. https://doi.org/10.1080/01621459.1968.10480934

Solomon, A., and Newman, M. (2012). Reconciling disparate twentieth-century Indo-Pacific ocean temperature trends in the instrumental record. Nat. Climate Change, 2(9), 691-699. https://doi.org/10.1038/nclimate1591

Taylor, K. E. (2001). Summarizing multiple aspects of model performance in a single diagram. J. Geophys. Res. Atmos., 106(D7), 7183-7192. https://doi.org/10.1029/2000JD900719

Taylor, K. E., Stouffer, R. J., and Meehl, G. A. (2012). An overview of CMIP5 and the experiment design. Bull. Am. Meteor. Soc., 93(4), 485-498. https://doi.org/10.1175/bams-d-11-00094.1

Theil, H. (1992). A rank-invariant method of linear and polynomial regression analysis. In B. Raj, et al. (Eds.), Henri Theil's Contributions to Economics and Econometrics: Econometric Theory and Methodology (pp. 345-381). Dordrecht: Springer. https://doi.org/10.1007/978-94-011-2546-8_20

Yang, C. X., Giese, B. S., and Wu, L. X. (2014). Ocean dynamics and tropical Pacific climate change in ocean reanalyses and coupled climate models. J. Geophys. Res. Oceans, 119(10), 7066-7077. https://doi.org/10.1002/2014JC009979

Yeh, S. W., Kug, J. S., Dewitte, B., Kwon, M. H., Kirtman, B. P., and Jin, F. F. (2009). El Niño in a changing climate. Nature, 461(7263), 511-514. https://doi.org/10.1038/nature08316

Zhang, W. J., Li, J. P., and Zhao, X. (2010). Sea surface temperature cooling mode in the Pacific cold tongue. J. Geophys. Res. Oceans, 115(C12), C12042. https://doi.org/10.1029/2010jc006501

Zhang, W. J., and Jin, F. F. (2012). Improvements in the CMIP5 simulations of ENSO-SSTA meridional width. Geophys. Res. Lett., 39(23), L23704. https://doi.org/10.1029/2012GL053588

Zhang, W. J., Jin, F. F., Zhao, J. X., Qi, L., and Ren, H. L. (2013). The possible influence of a nonconventional El Niño on the severe autumn drought of 2009 in southwest China. J. Climate, 26(21), 8392-8405. https://doi.org/10.1175/JCLI-D-12-00851.1

Zhang, W. J., Jin, F. F., and Turner, A. (2014). Increasing autumn drought over southern China associated with ENSO regime shift. Geophys. Res. Lett., 41(11), 4020-4026. https://doi.org/10.1002/2014GL060130

Zheng, F., Fang, X. H., Yu, J. Y., and Zhu, J. (2014). Asymmetry of the Bjerknes positive feedback between the two types of El Niño. Geophys. Res. Lett., 41(21), 7651-7657. https://doi.org/10.1002/2014GL062125

Zheng, F., Li, J. P., Feng, J., Li, Y. J., and Li, Y. (2015). Relative importance of the austral summer and autumn SAM in modulating Southern Hemisphere extratropical autumn SST. J. Climate, 28(20), 8003-8020. https://doi.org/10.1175/JCLI-D-15-0170.1

Zheng, F., Fang, X. H., Zhu, J., Yu, J. Y., and Li, X. C. (2016). Modulation of Bjerknes feedback on the decadal variations in ENSO predictability. Geophys. Res. Lett., 43(24), 12560-12568. https://doi.org/10.1002/2016GL071636

Zheng, F., and Yu, J. Y. (2017). Contrasting the skills and biases of deterministic predictions for the two types of El Niño. Adv. Atmos. Sci., 34(12), 1395-1403. https://doi.org/10.1007/s00376-017-6324-y 